University of Wollongong

Research Online

Australian Institute for Innovative Materials -

Papers

Australian Institute for Innovative Materials

$1-1-2017$

Structure-Property Relationships of Organic Electrolytes and Their Effects on Li/S Battery Performance

Mohammad Kaiser

University of Wollongong, mrk912@uowmail.edu.au

Shulei Chou

University of Wollongong, shulei@uow.edu.au

Hua-Kun Liu

University of Wollongong, hua@uow.edu.au

Shi Xue Dou

University of Wollongong, shi@uow.edu.au

Chunsheng Wang

University of Maryland

See next page for additional authors

Follow this and additional works at: https://ro.uow.edu.au/aiimpapers

Part of the Engineering Commons, and the Physical Sciences and Mathematics Commons

Research Online is the open access institutional repository for the University of Wollongong. For further information contact the UOW Library: research-pubs@uow.edu.au 


\title{
Structure-Property Relationships of Organic Electrolytes and Their Effects on Li/S Battery Performance
}

\begin{abstract}
Electrolytes, which are a key component in electrochemical devices, transport ions between the sulfur/ carbon composite cathode and the lithium anode in lithium-sulfur batteries (LSBs). The performance of a LSB mostly depends on the electrolyte due to the dissolution of polysulfides into the electrolyte, along with the formation of a solid-electrolyte interphase. The selection of the electrolyte and its functionality during charging and discharging is intricate and involves multiple reactions and processes. The selection of the proper electrolyte, including solvents and salts, for LSBs strongly depends on its physical and chemical properties, which is heavily controlled by its molecular structure. In this review, the fundamental properties of organic electrolytes for LSBs are presented, and an attempt is made to determine the relationship between the molecular structure and the properties of common organic electrolytes, along with their effects on the LSB performance.
\end{abstract}

\section{Keywords}

organic, battery, electrolytes, performance, their, effects, li/s, relationships, structure-property

Disciplines

Engineering | Physical Sciences and Mathematics

\section{Publication Details}

Kaiser, M. Rejaul., Chou, S., Liu, H., Dou, S., Wang, C. \& Wang, J. (2017). Structure-Property Relationships of Organic Electrolytes and Their Effects on Li/S Battery Performance. Advanced Materials, Online first 1700449-1-1700449-17.

\section{Authors}

Mohammad Kaiser, Shulei Chou, Hua-Kun Liu, Shi Xue Dou, Chunsheng Wang, and Jiazhao Wang 


\title{
WILEY-VCH
}

DOI: 10.1002/ ((please add manuscript number))

Article type: Mini Review

\section{Structure-Property Relationships of Organic Electrolytes and their Effects on Li/S Battery Performance}

\author{
Mohammad Rejaul Kaiser ${ }^{a}$, Shulei Chou ${ }^{a}$, Hua-Kun Liu ${ }^{a}$, Shi-Xue Dou ${ }^{a}$, Chunsheng Wang ${ }^{b}$ \\ and Jiazhao Wang ${ }^{a}$ * \\ anstitute for Superconducting and Electronic Materials, University of Wollongong, \\ Wollongong, NSW 2522, Australia.*Email: jiazhao@uow.edu.au \\ ${ }^{\mathrm{b}}$ Department of Chemical and Biomolecular Engineering, University of Maryland, College \\ Park, Maryland, 20742, United States.
}

Electrolyte, which is a key component in electrochemical devices, transports ions between the sulfur/carbon composite cathode and the lithium anode in lithium-sulfur batteries (LSBs). The performance of a LSB mostly depends on the electrolyte, due to the dissolution of polysulfides into the electrolyte, along with the formation of a solid electrolyte interphase (SEI). The selection of electrolyte and its functionality during charging and discharging is intricate and involves multiple reactions and processes. The selection of the proper electrolyte, including the solvents and salts, for LSBs strongly depends on its physical and chemical properties, which is heavily controlled by its molecular structure. In this mini review, the fundamental properties of organic electrolytes for LSBs are presented, and an attempt is made to determine the relationship between the molecular structure and the properties of common organic electrolytes, along with their effects on the LSB performance.

\section{Introduction}

With the emergence of new portable electronic devices and of hybrid and electric vehicles in our daily lives, the demand for high-energy batteries has increased rapidly. Moreover, storing renewable energy (e.g., solar, wind, wave, etc.) when it is abundant and available also requires high-energy batteries. Conventional Li-ion batteries using a lithium metal oxide 


\section{WILEY-VCH}

cathode and graphite anode, which were introduced by Sony in 1991, feature a theoretical specific energy of $400 \mathrm{Wh} \mathrm{kg}^{-1[1]}$. In practice, only half of the theoretical specific energy has been achieved to date, which is unable to meet the current requirements for electric vehicles and hybrid electric vehicles ${ }^{[2,3]}$. Moreover, metal oxide batteries contain heavy transition metals, which not only reduce the specific capacity but also increase the overall cost of the battery due to the scarcity of heavy transition metals in the earth's crust. To solve this problem, researchers have focused on different cathode materials with high theoretical capacity, such as sulfur. Although studies on the Li/S system have been ongoing for the last thirty years, the system has yet to be commercialized due to many unsettled issues. The most well-known problems of the Li/S system are its short cycle life, low coulombic efficiency, poor safety, and a high self-discharge rate, which are related to the dissolution of longer chain polysulfides in organic electrolytes ${ }^{[4]}$. On the other hand, the dissolution of longer chain polysulfides is equally important for the performance of the Li/S system to overcome the challenges of low ionic and electronic conductivity of sulfur and lithium sulfide, specifically in order to achieve a higher discharge voltage ${ }^{[5]}$. This appears to be a Goldilocks problem, where the dissolution of longer chain polysulfides has both positive and negative effects. Numerous research studies have been conducted on the cathode, anode, and electrolyte to minimize the challenges, and significant advances have been achieved. There are some excellent reviews on Li/S batteries, specifically on cathodes, which cover the current ongoing research and understanding of the $\mathrm{Li} / \mathrm{S}$ system ${ }^{[6,7,8,9]}$. These papers have meticulously reviewed the correlation between the electrode morphology and the cycling performance, along with the effects of different conducting additives, binders, and interlayers. Very few papers available from open sources have focused on the effects of different electrolytic components (e.g., solvents, salts, additives, etc.) on the cycling performance of the $\mathrm{Li} / \mathrm{S}$ system, except for these three review papers ${ }^{[4,5,10]}$, which are solely focused on the effects of different electrolytes on the cycling performance of $\mathrm{Li} / \mathrm{S}$ batteries. No review papers were 


\section{WILEY-VCH}

found that comprehensively discuss the structure-property relationships of the electrolytic components (solvents, salts and additives) that dictate the cycling performance of any electrochemical system. This has motivated us to write this mini review, which explains how the molecular structures of solvents and salts affect the electrochemical performance of the cells containing them. This mini review also focuses on the common physicochemical properties that should be considered during the selection of electrolytes and the relationship between the molecular structure and the respective physicochemical properties.

\section{Principles and background of the lithium/sulfur battery system}

A battery is an electrochemical device that can store electrical energy through chemical means and can deliver the electrical energy through chemical reaction when needed. In lithium-sulfur batteries (LSBs), electrical energy can be stored in the sulfur electrode through a chemical reaction between lithium and sulfur. Like all other rechargeable batteries, LSBs also consist of an anode, a cathode, and electrolyte. Figure 1 describes the components and the operating principle of LSBs.

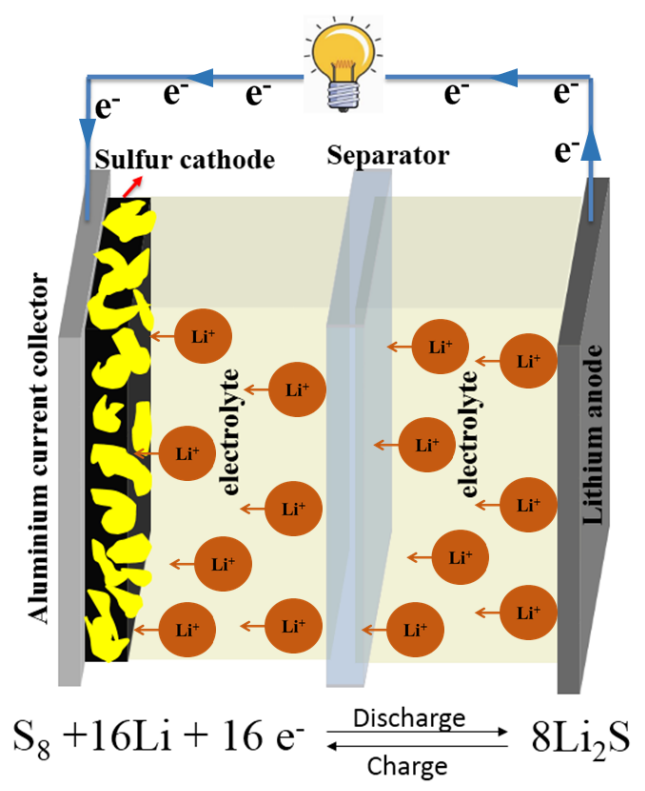

Figure 1 Schematic diagram of lithium-sulfur (Li-S) cell showing its components and the chemical reaction. 


\section{WILEY-VCH}

After fabrication, the Li-S cell is in a charged state and will discharge when connected with a load. During discharging, oxidation occurs at the anode surface where lithium metal atoms form lithium ions $\left(\mathrm{Li}^{+}\right)$by losing one electron each. The electrons then pass through the load and reach the cathode, where sulfur is reduced by accepting electrons and lithium ions to form lithium sulfide. During charging, however, the opposite phenomena occur, i.e., the oxidation of sulfur and the reduction of lithium.

Even though the overall reaction is shown as a single step, in reality, the reaction has multiple steps. The theoretical capacity of a Li-S full cell is $1166 \mathrm{mAh} / \mathrm{g}$, which is equal to $1166 \mathrm{Ah} / \mathrm{kg}$. The average discharge voltage plateau (since the discharge shows multiple plateaus) is $2.2 \mathrm{~V}$, and hence, the gravimetric energy density of a Li-S cell is $=2.2 \times 1166 \approx 2600 \mathrm{Wh} / \mathrm{kg}$. The average volumetric energy density of a Li-S full cell is $2200 \mathrm{Wh} / \mathrm{L}$. As mentioned earlier, the reduction of sulfur has multiple steps, which include both single-phase and two-phase reduction. The details of the reduction products, steps, and mechanism are stated below and are shown in Figure 2.

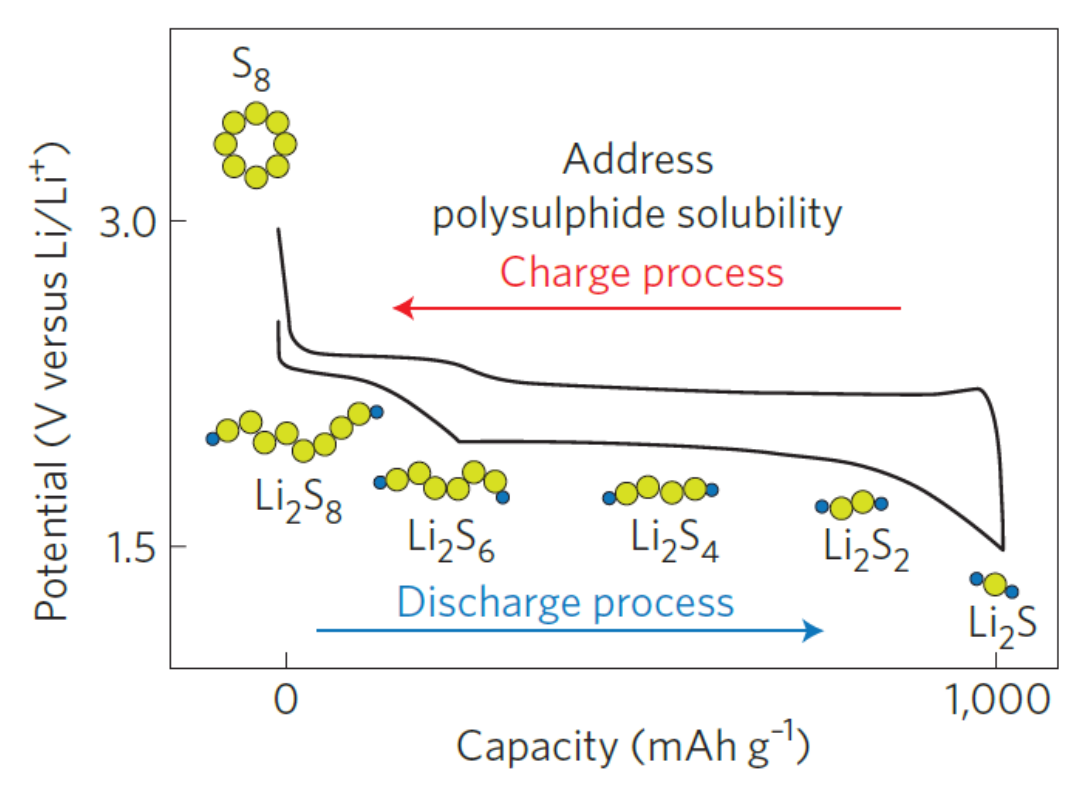

Figure 2 The charge-discharge curve shows the oxidation and reduction of sulfur ${ }^{[1]}$.

Reprinted with permission. Copyright 2012 Nature Publishing Group. 


\section{WILEY-VCH}

Step 1: A solid-liquid two-phase reaction where $\mathrm{S}_{8}$ is reduced to $\mathrm{Li}_{2} \mathrm{~S}_{8}$. The reduction product, which is $\mathrm{Li}_{2} \mathrm{~S}_{8}$, is highly soluble in liquid organic electrolyte due to its high polarity. This liquid solution acts as a catholyte for further reduction.

Step 2: A liquid-liquid single-phase reduction where dissolved $\mathrm{Li}_{2} \mathrm{~S}_{8}$ is reduced to $\mathrm{Li}_{2} \mathrm{~S}_{6}$ and $\mathrm{Li}_{2} \mathrm{~S}_{4}$

Step 3: A liquid-solid two-phase reaction where the dissolved $\mathrm{Li}_{2} \mathrm{~S}_{6}$ and $\mathrm{Li}_{2} \mathrm{~S}_{4}$ polysulfides are further reduced to insoluble $\mathrm{Li}_{2} \mathrm{~S}_{2}$.

Step 4: A solid-solid single-phase reaction where insoluble $\mathrm{Li}_{2} \mathrm{~S}_{2}$ is reduced to $\mathrm{Li}_{2} \mathrm{~S}$.

There is huge controversy about the reaction mechanism and steps of the Li-S system. Few in situ characterizations have been done; however, it was found that the formation of $\mathrm{Li}_{2} \mathrm{~S}_{6}$ along with $\mathrm{Li}_{2} \mathrm{~S}_{8}$ occurs during the formation of the first plateau. Moreover, the individual steps do not produce any one specific product, but instead produce multiple reduction products ${ }^{[11]}$. Researchers are still struggling to find concrete proof of the reduction mechanism. Very recently, Wild et al. ${ }^{[9]}$ wrote a critical review of the reduction mechanism and attempted to model the polysulfides. Their model output the reduction products and the corresponding voltages, which are shown in Table $1^{[9]}$.

Table 1 Reactions and their corresponding voltages during charging and discharging of an $\operatorname{LSB}^{[9]}$.

\begin{tabular}{ccc}
\hline Step & Corresponding reaction & Voltage \\
\hline 1 & $\begin{array}{c}\mathrm{S}_{8}+2 \mathrm{Li}^{+}+2 \mathrm{e} \leftrightarrow \leftrightarrow \mathrm{Li}_{2} \mathrm{~S}_{8} \\
3 \mathrm{~L}_{2} \mathrm{~S}_{8}+2 \mathrm{Li}^{+}+2 \mathrm{e} \leftrightarrow 4 \mathrm{Li}_{2} \mathrm{~S}_{6}\end{array}$ & $>2.3 \mathrm{~V}$ \\
\hline 2 & $2 \mathrm{Li}_{2} \mathrm{~S}_{6}+2 \mathrm{Li}^{+}+2 \mathrm{e} \leftrightarrow 3 \mathrm{Li}_{2} \mathrm{~S}_{4}$ & 2.3 to $2.1 \mathrm{~V}$ \\
\hline 3 & $\mathrm{Li}_{2} \mathrm{~S}_{4}+2 \mathrm{Li}^{+}+2 \mathrm{e}^{-} \leftrightarrow 2 \mathrm{Li}_{2} \mathrm{~S}_{2}$ & \\
\hline 4 & $\mathrm{Li}_{2} \mathrm{~S}_{4}+6 \mathrm{Li}^{+}+6 \mathrm{e} \leftrightarrow 4 \mathrm{Li}_{2} \mathrm{~S}$ & \\
\hline $\mathrm{Li}_{2} \mathrm{~S}_{2}+2 \mathrm{Li}^{+}+2 \mathrm{e} \leftrightarrow \leftrightarrow 2 \mathrm{Li}_{2} \mathrm{~S}$ & $<1.9 \mathrm{~V}$ \\
\hline
\end{tabular}




\section{WILEY-VCH}

More simply, the first two steps, which involve the reduction of $\mathrm{S}_{8}$ to $\mathrm{S}_{8}{ }^{2-}, \mathrm{S}_{6}{ }^{2-}$, and $\mathrm{S}_{4}{ }^{2-}$, resemble the first plateau of the discharge curve, while the last two steps, where $\mathrm{S}_{4}{ }^{2-}$ is reduced to $\mathrm{S}_{2}{ }^{2-}$ and $\mathrm{S}^{2-}$, form the second plateau of the discharge curve, which is shown in Figure 2.

\section{Key challenges for the lithium/sulfur system and possible solutions}

Elemental sulfur has been used as a cathode since 1962 when Herbet and Ulam fabricated a sulfur-based electric dry cell ${ }^{[12]}$. Over the following forty years, sulfur batteries did not gain much attention and were only used as primary batteries due to their intricate chemistry ${ }^{[13,14]}$. With the advancement of technology and organic chemistry, however, interest in the Li-S system was revived, which attracted a number of researchers in the early 2000s. Although the $\mathrm{Li} / \mathrm{S}$ system is a hot topic in current research and numerous researchers all over the world are working on it, researchers have yet to solve all the challenges in order to commercialize the system. There are three main challenges that need to be solved for the commercialization of LSBs.

The first challenge is the insulating nature of sulfur. Sulfur is not electrically conductive at all and shows an electrical conductivity of $5 \times 10^{-30} \mathrm{~S} \cdot \mathrm{cm}^{-1}[15,16,17,18,19,20,21]$, which leads to poor active material accessibility and low utilization of sulfur in the electrode. The second challenge is the reduction product of sulfur. When sulfur is fully reduced (during discharging), lithium sulfide $\left(\mathrm{Li}_{2} \mathrm{~S}\right)$ is formed, which is not only electrically insulating but also ionically insulating ${ }^{[22,23,24,25]}$. Moreover, when sulfur is reduced to $\mathrm{Li}_{2} \mathrm{~S}$, it is deposited on the surface of the cathode, and once a thin $\mathrm{Li}_{2} \mathrm{~S}$ layer completely covers the whole electrode, further lithiation is largely impeded, causing the voltage to decrease rapidly. Thus, the complete conversion of sulfur to $\mathrm{Li}_{2} \mathrm{~S}$ rarely occurs, and in every case, the discharge capacity is less than $80 \%$ of the theoretical capacity ${ }^{[9]}$. Third, and the most fatal challenge by far, polysulfide 


\section{WILEY-VCH}

can dissolve into the electrolyte. Polysulfide anions, which are readily formed as reaction intermediates, are highly soluble in organic electrolyte solvent ${ }^{[24]}$, where they then create a concentration gradient in the electrolyte and move to the anode surface through diffusion. These soluble species are then reduced to $\mathrm{Li}_{2} \mathrm{~S}$, which is insoluble in the electrolyte; thus, $\mathrm{Li}_{2} \mathrm{~S}$ is precipitated out of the electrolyte and forms a passivation layer at the lithium anode surface, which causes the loss of active material and increases the impedance of the Li-S cell. Furthermore, the polysulfide dissolution and precipitation process alters the morphology of the cathode in each cycle, such that it does not return to its initial morphological structure, leading to $\sim 80 \%$ volume expansion from $\mathrm{S}$ to $\mathrm{Li}_{2} \mathrm{~S}$, which induces strain inside the electrode and results in low active material utilization and poor cycle life ${ }^{[26,27,28,29]}$. Polysulfide dissolution is also responsible for the well-known "shuttle" phenomenon, where long-chain polysulfides diffuse to the surface of the lithium anode due to the concentration gradient and are reduced to short-chain polysulfides, which also creates a concentration gradient on the anode side. The short-chain polysulfides can then move back to the cathode where they are oxidized to long-chain polysulfides, again creating a concentration gradient. This parasitic process occurs continuously and creates an internal "shuttle" phenomenon [30, 31, 32, 33, 34, 35, 36, 37, 38, 39, 40,41, 42, 43, 44, 45, 46]. The general mechanism of the shuttle phenomenon involving organic electrolyte is shown in Figure 3, which is redrawn from the concept that Akridge et al. proposed $^{[47]}$. 


\section{WILEY-VCH}

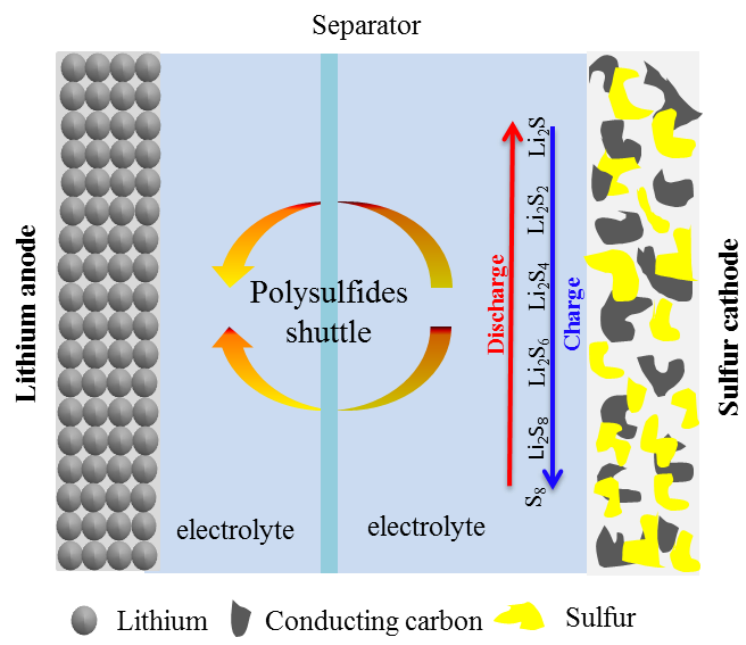

Figure 2 Schematic diagram of the shuttle phenomenon of polysulfides in Li/S batteries during charging-discharging.

To be precise, this shuttle phenomenon, along with its parasitic reactions, causes the following problems: (1) the consumption or loss of active material, (2) the corrosion of the $\mathrm{Li}$ metal anode, and (3) the polarization of the $\mathrm{Li}$ anode when insoluble $\mathrm{Li}_{2} \mathrm{~S}$ and $\mathrm{Li}_{2} \mathrm{~S}_{2}$ are formed and deposited on the Li surface. In other words, this shuttle phenomenon leads to low active material utilization, low coulombic efficiency, and short cycle life for the Li-S system $[48,49]$.

The first challenge in overcoming the insulating nature of sulfur in the $\mathrm{Li} / \mathrm{S}$ system can be mitigated by the addition of conductive carbons, which have very high electronic and ionic conductivity, along with high voltage stability, low density, and chemical inertness ${ }^{[37]}$. Moreover, different chemical and mechanical processes for the fabrication of sulfur/carbon composites and innovative electrode design help increase the active material accessibility and utilization ${ }^{[50,51]}$. The second and third challenges are, however, closely related to the electrolyte, because the initial discharge products (longer chain polysulfides) are soluble in most organic electrolytes, which leads to $\mathrm{Li}_{2} \mathrm{~S}$ deposition and the shuttle phenomenon. The selection of a suitable electrolyte (both solvents and salts) can abate the challenges and advance the commercialization of the $\mathrm{Li} / \mathrm{S}$ system ${ }^{[52,53,54]}$. 


\section{WILEY-VCH}

\section{Fundamentals of liquid organic electrolyte for the $\mathrm{Li} / \mathrm{S}$ system}

The electrolyte is one of the most important components in an electrochemical device, along with the anode and cathode. The main task of the electrolyte is to transfer ions between the two electrodes. However, the emergence of the Li-ion system and more advanced systems beyond $\mathrm{Li}$, which can provide high energy and high power, have changed this view of the functionality of the electrolyte. The electrolyte can not only transport ions but can also help form a solid electrolyte interphase (SEI) on the electrode surface, which will prevent reactions between the electrolyte and the electrodes. Organic liquid electrolytes mainly consist of two or three substances, namely, the solvent and the salt, although in some cases, additives are also included. For the Li/S system, the theoretical voltage window between sulfur and lithium is less than $3 \mathrm{~V}$ (vs. $\mathrm{Li} / \mathrm{Li}^{+}$), which facilitates the use of several organic solvents as the electrolyte in the Li/S system. Various forms of polysulfides (e.g., short chain, long chain, radicals) have been found to form during charging and discharging, which react with almost all the organic solvents that fit into that electrochemical window ${ }^{[10]}$. This reactivity of polysulfides, sulfides, and sulfur radicals limits the selection of organic solvents for the $\mathrm{Li} / \mathrm{S}$ system to an extremely narrow range. Before we discuss the structure-property relationships of organic electrolytes, it is important to mention the fundamental properties of electrolytes, specifically the solvents and salts.

\subsection{Properties of solvents}

All protic solvents release hydrogen gas at $2.2 \mathrm{~V}$, which makes them unsuitable as electrolyte solvents for the $\mathrm{Li} / \mathrm{S}$ system. In addition to the large electrochemical voltage window, liquid organic solvents should meet a number of criteria to be effective electrolyte solvents, notably, high ionic conductivity, low electrical conductivity, high transference number, high and low temperature stability, high dielectric permittivity, low viscosity, inertness to all other cell components (e.g., the separator, electrode, spacer, etc.), low flammability, low toxicity, and 


\section{WILEY-VCH}

finally, low cost ${ }^{[55]}$. It is difficult to find a unary solvent that possesses all these properties; however, a number of binary and ternary solvents exhibit the aforementioned properties.

Organic carbonates and esters, which meet almost all the criteria, are widely used in Li-ion batteries. Mixtures of cyclic (ethylene carbonate and propylene carbonate) and linear carbonates (dimethyl carbonate and diethyl carbonate), which have high and low viscosity, respectively, feature the optimum properties of an effective electrolyte solvent and have been used in Li-ion batteries for two decades. It was expected that these electrolytes could also be used in the $\mathrm{Li} / \mathrm{S}$ system. However, the polysulfide intermediates in the multiple reduction steps irreversibly react with carbonates and esters to form a sulfide carbonate complex, which makes these electrolytes unsuitable for the $\mathrm{Li} / \mathrm{S}$ system. Figure 4 shows the reaction mechanism proposed by Gao et al. ${ }^{[56]}$.
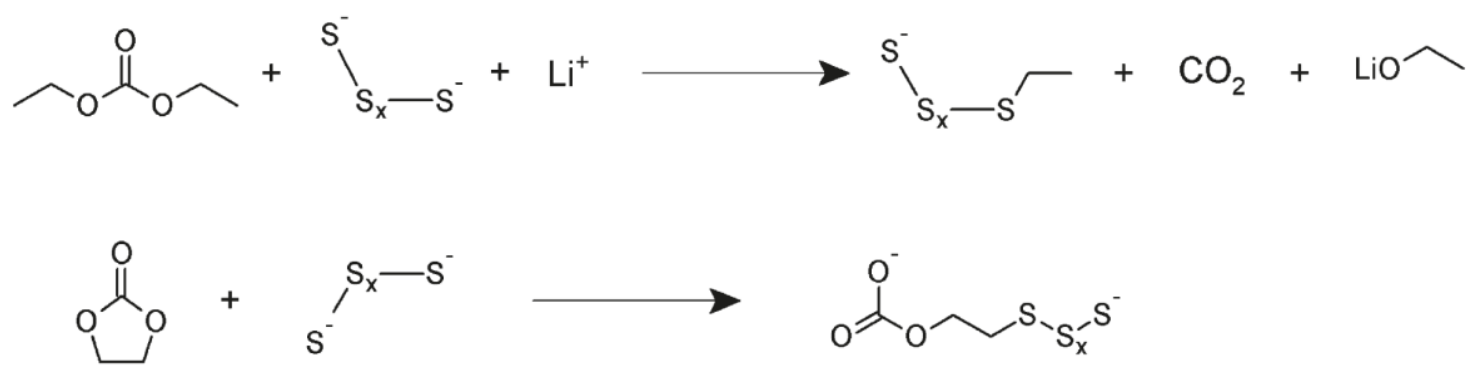

Figure 4: Proposed reaction mechanism of polysulfides in carbonate electrolyte ${ }^{[53]}$. Reprinted with permission. Copyright 2011, American Chemical Society.

Figure 4 shows that nucleophilic polysulfides attack the single-bonded carbon atoms attached to the oxygen atoms of the linear diethyl carbonate (DEC) and cyclic ethylene carbonate (EC) molecules, which are partially positive and act as electrophiles due to electron attraction by the highly electronegative oxygen atoms. The central carbon atom, which is double bonded to an oxygen atom, is stabilized, however, by its resonance structure and shows steric hindrance, and thus it is unable to react with polysulfide nucleophiles. A similar mechanism can also be 


\section{WILEY-VCH}

found for ester-based electrolytes. Moreover, ester-based electrolytes show very low dielectric permittivity and dipole moments, making them unsuitable to dissolve salts, and hence, reduces their ionic conductivity ${ }^{[57]}$.

Ethers, which are unsuitable electrolyte solvents for Li-ion batteries due to their instability above $4 \mathrm{~V}$, have been considered as potential electrolytes for the Li/S system. Most ethers are stable in liquid form over a wide range of temperatures and have low viscosity, resulting in high ionic conductivity ${ }^{[58]}$. Most importantly, ethers do not react with polysulfides or sulfur radicals during charging and discharging processes, which makes them suitable electrolytes for the Li/S system ${ }^{[56]}$. The physical and chemical properties of common ether solvents are listed in Table $2^{[55]}$.

Table 2 Physicochemical properties of ether-based solvents for Li/S batteries.

\begin{tabular}{|c|c|c|c|c|c|}
\hline Solvent & Molecular formula & $\begin{array}{c}\text { Melting } \\
\text { temperature }\left[{ }^{\circ} \mathrm{C}\right]\end{array}$ & $\begin{array}{c}\text { Boiling } \\
\text { temperature }\left[{ }^{\circ} \mathrm{C}\right]\end{array}$ & $\begin{array}{l}\text { Viscosity at } \\
25^{\circ} \mathrm{C}\end{array}$ & $\begin{array}{l}\text { Dielectric } \\
\text { permittivity }\end{array}$ \\
\hline $\begin{array}{l}\text { Dimethoxy methane } \\
\text { (DMM) }\end{array}$ & $\mathrm{CH}_{3}$ & -105 & 41 & 0.33 & 2.7 \\
\hline $\begin{array}{l}\text { Diethoxy ethane } \\
\text { (DEE) }\end{array}$ & & -74 & 121 & - & - \\
\hline $\begin{array}{l}\text { Dimethoxy ethane } \\
\text { (DME) }\end{array}$ & $\mathrm{CH}_{3}$ & -58 & 84 & 0.46 & 7.2 \\
\hline $\begin{array}{l}\text { Tetrahydrofuran } \\
\text { (THF) }\end{array}$ & & -109 & 66 & 0.46 & 7.2 \\
\hline $\begin{array}{l}\text { 1,3-Dioxolane } \\
\text { (DOL) }\end{array}$ & & -95 & 78 & 0.59 & 7.1 \\
\hline $\begin{array}{l}\text { 2-Methyl- } \\
\text { tetrahydrofuran }\end{array}$ & & -137 & 80 & 0.47 & 6.2 \\
\hline $\begin{array}{l}\text { 2-Methyl-1,3- } \\
\text { dioxolane (DOL) }\end{array}$ & & - & - & 0.54 & 4.39 \\
\hline $\begin{array}{l}\text { 4-Methyl-1,3- } \\
\text { dioxolane (DOL) }\end{array}$ & & -125 & 85 & 0.60 & 6.8 \\
\hline
\end{tabular}




\section{WILEY-VCH}

Table 2 shows that almost all ether-based electrolytes (both linear and cyclic) exhibit similar physicochemical properties, although cyclic ethers have been shown to have better cycling performance than linear ethers ${ }^{[58]}$. Importantly, cyclic ethers have higher viscosity than linear ethers, which impedes the movement of ions and results in low ionic conductivity. Thus, a mixture of linear and cyclic ethers is generally used as the electrolyte in Li/S systems. Among the linear ethers, dimethoxyethane (DME) is chosen due to its high dielectric permittivity, which helps dissolve a large amount of Li-based salts for better ionic movement. Among the cyclic ethers, THF and DOL show higher dielectric permittivity. DOL is selected, however, due to its low dipole moment, which is approximately $1.25 \mathrm{D}$ compared to $1.7 \mathrm{D}$ for THF. The dipole moment of a molecule strongly depends on the atoms and their arrangement in the molecule. Even though DOL contains two oxygen atoms, which are highly electronegative, its dipole moment is lower than that of THF, which has only one oxygen atom. Figure 5a shows the molecular structures and atomic arrangements of THF and DOL. The overall dipole moment of a molecule is approximately the vector sum of the bond dipole moments. In DOL, the two opposite bond dipole moments mitigate each other, and the resultant dipole moment is lower than that of THF. Because nucleophilic polysulfides have a higher tendency to react with molecules with higher dipole moments, THF is avoided as the solvent.
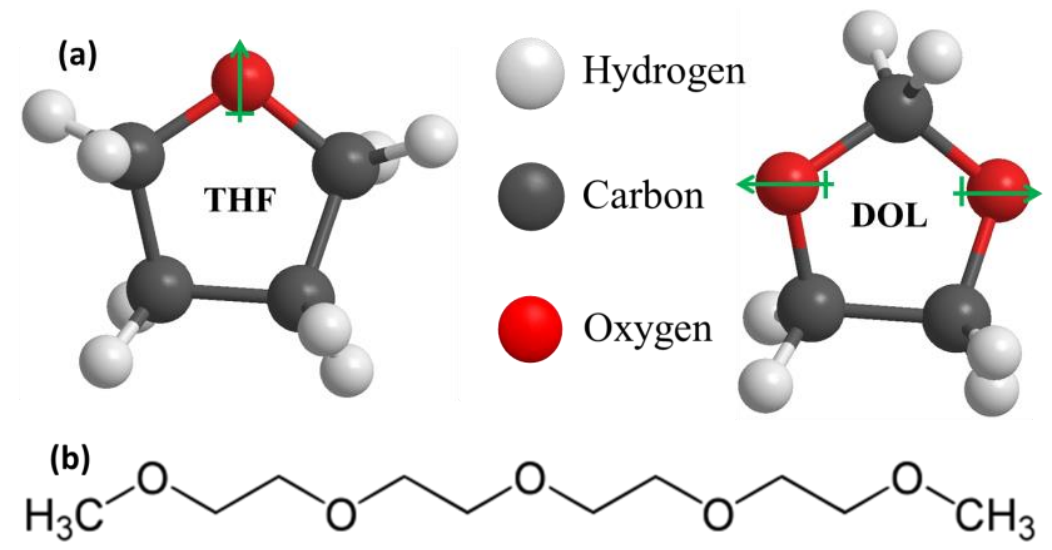

Figure 5: (a) Directions of the dipole moments in THF and DOL and (b) the molecular structure of TEGDME. 


\section{WILEY-VCH}

In addition to ethers, linear and cyclic glymes are also used as solvents in Li/S systems, and among them, tetraethylene glycol dimethyl ether (tetraglyme or TEGDME) and polyethylene glycol dimethyl ether (PEGDME) are notable ${ }^{[59,60]}$. All glymes have a very wide temperature stability $\left(-27{ }^{\circ} \mathrm{C}\right.$ to $\left.275{ }^{\circ} \mathrm{C}\right)$ and high dielectric permittivity ( 6.7). Nevertheless, their viscosity is 8 to 10 times higher than that of both linear and cyclic ethers, which reduces their ion transfer mobility. Moreover, viscous electrolytes have very low wettability and show very high impedance, which makes them unsuitable for $\mathrm{Li} / \mathrm{S}$ systems ${ }^{[60]}$.

As stated earlier and supported by the physicochemical properties observations, a single solvent cannot fulfill all the fundamental requirements for a suitable electrolyte. Moreover, in $\mathrm{Li} / \mathrm{S}$ systems, the electrolytes should have additional properties, such as polysulfide solubility, resistance to reactions with nucleophilic polysulfides, etc. ${ }^{[10]}$. A number of binary and ternary solvent mixtures containing combinations of different unary solvents have been used in the $\mathrm{Li} / \mathrm{S}$ system. Only a few of them, however, could meet the property requirements, which are shown in Table 3. Among binary mixtures, TEGDME/DOL and DME/DOL have been studied extensively ${ }^{[61,62,63,64,65,66,67]}$. Both TEGDME/DOL and DME/DOL were found to show very high discharge capacity. Though TEGDME/DOL has high viscosity and low ionic conductivity compared to DME/DOL, it has a synergistic effect on the ionic conductivity and polysulfide solubility. Henderson and Wesly ${ }^{[64]}$ showed that in the presence of the additional oxygen atoms in TEGDME (Figure $5 \mathrm{~b}$ ), $\mathrm{Li}^{+}$ions are solvated due to the attraction of the electronegative oxygen atoms. They also studied different ratios of TEGDME to DOL and found that the best performance was obtained with a ratio of 30:70, at which the sulfur utilization and ionic conductivity were maximized. 


\section{WILEY-VCH}

Table 3 Properties of common binary and ternary solvents for $\mathrm{Li} / \mathrm{S}$ battery electrolytes.

\begin{tabular}{lcccc}
\hline Solvent mixture & Ratio & Viscosity $[\mathrm{cP}]$ & lonic conductivity at $25^{\circ} \mathrm{C}[\mathrm{mS} / \mathrm{cm}]$ & Reference \\
\hline TEGDME/DOL & $33: 67$ & 1.9 & 8.5 & {$[66]$} \\
DME/DOL & $50: 50$ & 0.5 & 10.5 & {$[67]$} \\
THF/DOL/Toluene & $10: 30: 6$ & - & 3.5 & {$[14]$} \\
\hline
\end{tabular}

DME/DOL binary solvent may be the most popular and best-studied solvent for the Li/S system due to its attractive properties. Both DOL and DME have very high dielectric permittivity, low viscosity, high temperature stability and low molecular weight and are able to form a stable SEI on the Li metal surface. Because of these attractive properties, the binary solvent of DOL and DME has very high ionic conductivity, low viscosity, and high polysulfide solubility ${ }^{[63]}$, which makes it one of the best potential electrolyte solvents. In addition to binary solvents, ternary solvents have also been considered. Peled et al. ${ }^{[14]}$ studied a THF/DOL/toluene mixture, although its low ionic conductivity and dielectric permittivity limit its potential usage.

Gao et al. ${ }^{[56]}$ evaluated the cycling performance of a sulfur-carbon composite with different electrolyte solvents. Figure 6 shows that carbonate-based electrolytes exhibit no capacity after the first discharge cycle due to the irreversible reaction between the carbonates and polysulfides, which is triggered when the nucleophilic polysulfides attack the partially polarized and higher-dipole-moment carbonate-based solvents. In contrast, ether-based solvents show high initial capacity along with high capacity retention. Among the ether-based solvents, DOL/DME (1:1) shows a very high discharge capacity along with the highest capacity retention. The better physicochemical properties of DOL/DME (1:1), such as higher ionic conductivity, lower viscosity, and higher dielectric permittivity, which depend on the molecular structure of DOL and DME, afford a higher discharge capacity. Moreover, the chemical inertness of DOL and DME towards the polysulfides and sulfur radicals that evolve 


\section{WILEY-VCH}

during charging and discharging also play a pivotal role in achieving a higher discharge capacity and better capacity retention.

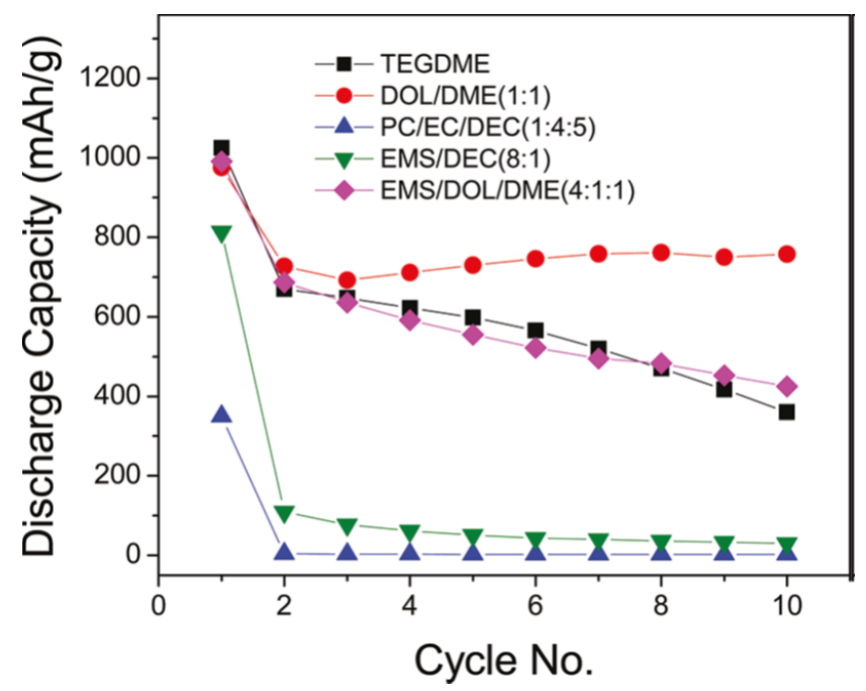

Figure 6: Effects of different solvents on the cycling performance of Li/S batteries ${ }^{[56]}$. Reprinted with permission. Copyright 2011, American Chemical Society.

Mikhaylik and co-workers ${ }^{[68]}$ studied the utilization of sulfur in ether-based electrolytes for Li/S batteries. They specifically focused on DOL, DME, and an equimolar mixture of DOL and DME. They found that the solvents DOL and DME, which have low viscosity, provide a balance among active material utilization (sulfur), rate capability, and high temperature stability over a wide operating range. DOL, which has a lower dipole moment due to the presence of two oxygen atoms with opposite dipole moment directions, has lower polysulfide solubility and slower kinetics than DME, but generates a more stable SEI on the anode (lithium) surface, which reduces the shuttle problem and affords high capacity retention (Figure 7). On the other hand, DME, which is a linear molecule with a higher dipole moment than DOL, shows higher reactivity towards lithium but exhibits higher polysulfide solubility and faster kinetics, which improve the cathode operation ${ }^{[68]}$, and thus DME-based batteries feature high initial capacity but lower capacity retention. Figure 7 also shows that the mixture 


\section{WILEY-VCH}

of these two electrolyte solvents (1:1 by volume) exhibits a synergistic effect related to the discharge capacity and cycle life.

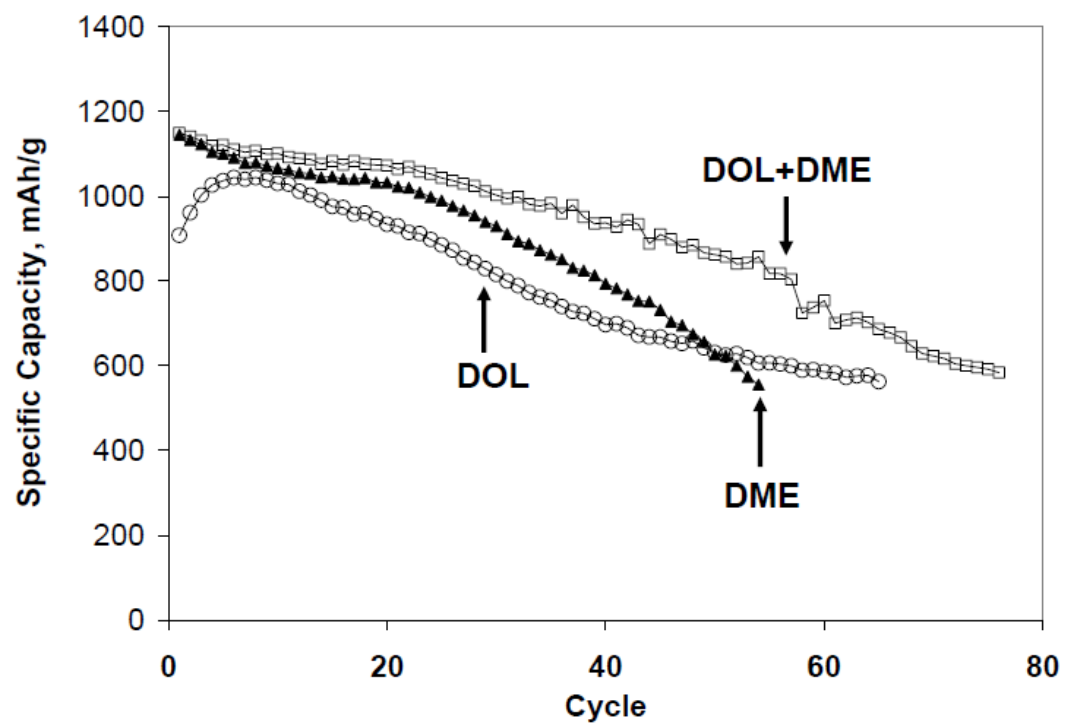

Figure 7 Cycling performance of DOL and DME-based electrolyte ${ }^{[65]}$. Reprinted with permission. Copyright 2010, Electrochemical Society.

In addition to the general properties of ideal electrolytes, such as viscosity, ionic conductivity, thermal stability, dielectric permittivity, and donor number, DOL and DME-based electrolyte possesses another significant property, which is the formation and stabilization of $\mathrm{S}_{3}{ }^{*}$ radicals [69, 70]. Other electrolytic solvents such as tetrahydrofuran (THF), which has a similar donor number and dielectric permittivity to DME, does not exhibit the stabilization of $\mathrm{S}_{3}{ }^{{ }^{*}-}$ radicals. It was hypothesized that the higher number of oxygen atoms in the molecular structure of DOL/DME can trigger the formation of stable $\mathrm{S}_{3}{ }^{*-}$ radicals ${ }^{[70,71]}$. It has been found, based on extensive observations, that the $\mathrm{S}_{3}{ }^{*-}$ radical helps to increase the active material utilization in the Li-S battery by completing the reduction and oxidation of sulfur and lithium sulfide $\left(\mathrm{Li}_{2} \mathrm{~S}\right)$, respectively ${ }^{[72]}$. Therefore, the DOL and DME-based electrolyte shows higher electrochemical performance. 


\section{WILEY-VCH}

An important observation was reported by Barchasz and co-workers ${ }^{[58]}$. They investigated the first discharge capacity with respect to the number of oxygen atoms present in the molecular structure of the solvent and found a linear relationship, where a greater number of oxygen atoms in the solvent increase the initial capacity. As seen in Figure 8, polyethylene glycol dimethoxyethane (PEGDME) shows the highest initial discharge capacity compared to other ethers that contain fewer oxygen atoms. The primary reason behind this finding is the six-fold coordination of lithium ions and the higher solvation capability of longer chain glymes. The secondary reason behind this finding is the greater solubility of shorter chain polysulfide in longer chain glymes, which reduces the passivation of the cathode surface and hence increases the active material utilization ${ }^{[58]}$. Even so, these longer chain glymes fail to exhibit high discharge capacity due to their higher viscosity. On the other hand, DOL (DIOX in Figure 8) shows a similar discharge capacity to TEGDME, even though DOL contains only two oxygen atoms. The mechanism behind this is still not fully understood, although it has been proposed that the cyclic molecular structure has a different dipole moment orientation than linear ethers and thus solvates lithium differently ${ }^{[58]}$.

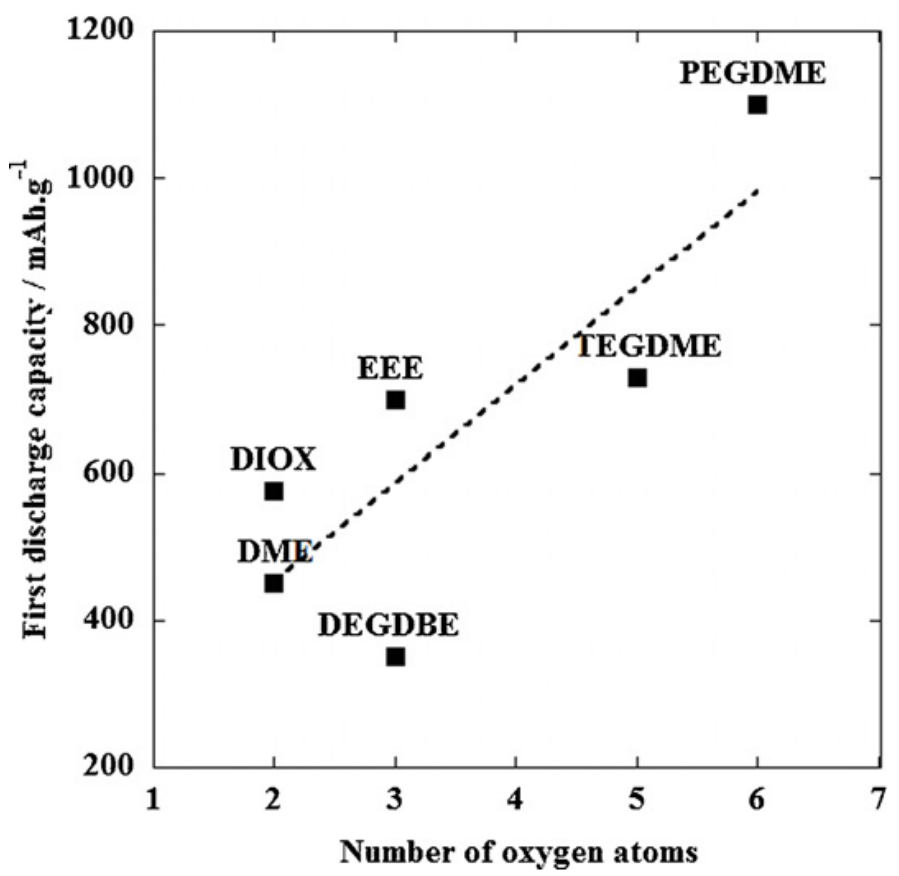




\section{WILEY-VCH}

Figure 8 First discharge capacity versus the number of oxygen atoms in the different electrolyte solvents ${ }^{[55]}$. Reprinted with permission. Copyright 2013, Elsevier.

\subsection{Salts for the $\mathrm{Li} / \mathrm{S}$ system}

Like solvents, salts should also possess certain properties to be ideal solutes for the solvents and to be a component of a suitable electrolyte. The general requirements of a salt that can be used as an electrolyte solute are as follows:

(1) The salt should have higher solubility in aprotic solvent, which means that the lattice energy of the salt should be low, so that without forming a hydrogen bond, the $\mathrm{Li}^{+}$ion can be dissociated from its counter anion. Moreover, after the formation of $\mathrm{Li}^{+}$, the anion should have a very high mobility in that solvent ${ }^{[55]}$.

(2) The anion should have very high stability and be inert to the solvent. This phenomenon is related to the lattice energy and solubility. Stable anions can form crystals with very low lattice energy and can dissociate very easily. In aprotic solvent, the dissociation of salts occurs by the attraction of lone pair electrons in the solvent to $\mathrm{Li}^{+}$. In other words, dissociation occurs through a Lewis acid-base interaction between the solvent and the salt ${ }^{[73]}$. Thus, conventional simple salts cannot be used due to their very high lattice energy, which cannot be overcome by the weak Lewis acid-base interaction.

(3) The salt, specifically the anions, should exhibit an optimum donor number (ability to donate electrons). Because higher donor number anions are strong Lewis bases and have a tendency to donate electrons, the stability of the anion is reduced. Moreover, higher donor number anions have a significant effect towards reducing the solubility 


\section{WILEY-VCH}

of polysulfides. In contrast, lower donor number anions may act as Lewis acids, which will react with nucleophilic polysulfides.

(4) Finally, both the anion and the cation should be inert towards other parts of the battery, specifically the separator, current collectors, and shells.

Table 4 Molecular structure, ionic conductivity, and donor number of common Li-salt anions

[57]. Reprinted with permission. Copyright-2015, RSC Publishing.

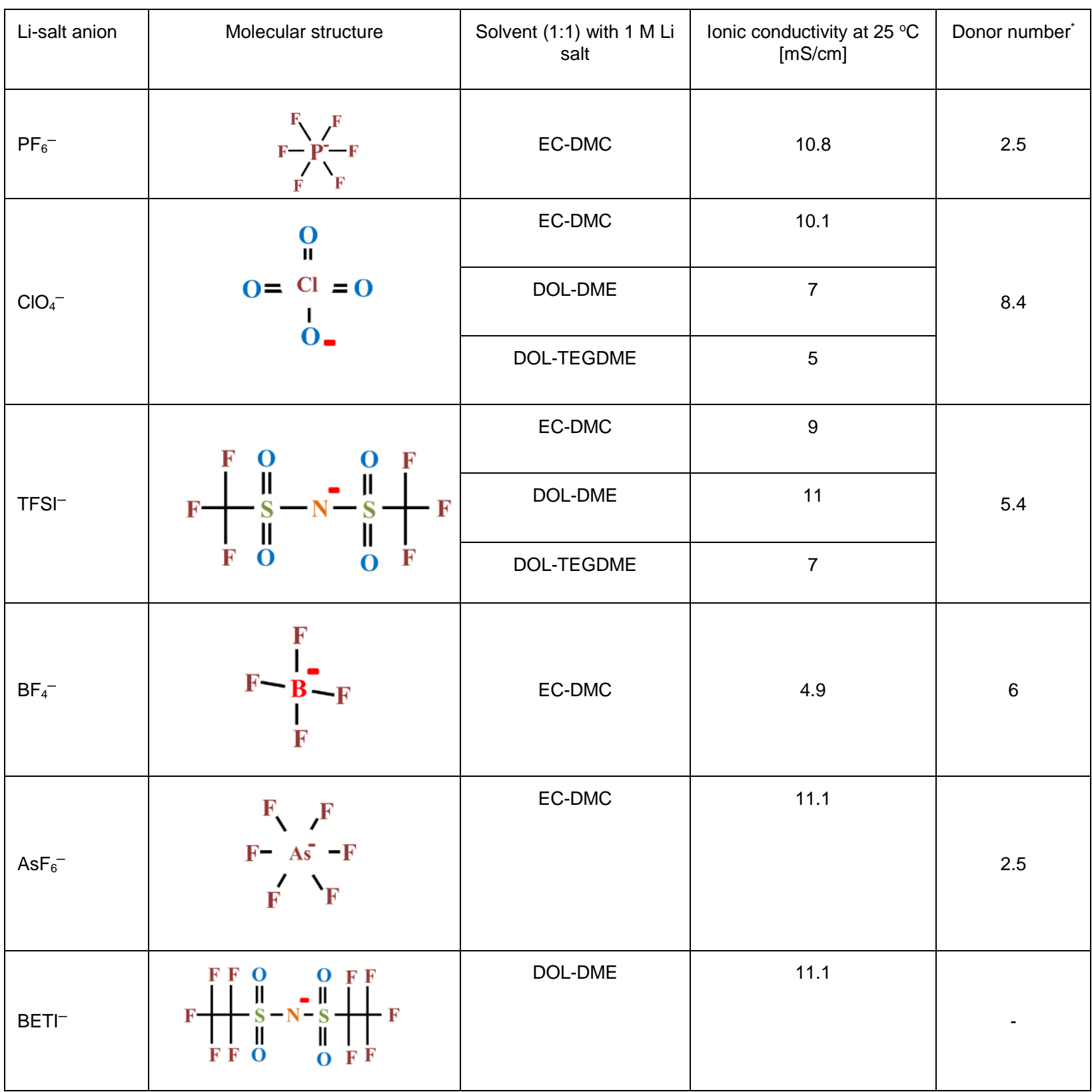




\section{WILEY-VCH}

* The donor number of different anions, measured using tetrabutylammonium (TBA+) as the counter cation ${ }^{[74]}$.

Table 4 summarizes the molecular structures and physicochemical properties of conventional lithium salts commonly used in $\mathrm{Li} / \mathrm{S}$ batteries. As mentioned earlier, carbonate-based electrolytes react with polysulfides and are not suitable for $\mathrm{Li} / \mathrm{S}$ systems, which makes $\mathrm{LiPF}_{6}$, $\mathrm{LiBF}_{4}$, and $\mathrm{LiAsF}_{6}$ incompatible ${ }^{[75]}$. These three salts generally show better physicochemical properties in carbonate-based solvents, although $\mathrm{LiPF}_{6}$ will induce the polymerization of DOL, greatly decreasing the ionic conductivity of the electrolyte, which makes it inappropriate for the $\mathrm{Li} / \mathrm{S}$ system. $\mathrm{LiClO}_{4}$, however, is compatible with both carbonate- and ether-based solvents and shows very low ionic conductivity in ether-based electrolyte compared to that in carbonate-based electrolyte. Moreover, chlorate anions $\left(\mathrm{ClO}_{4}^{-}\right)$are very strong oxidants (due to the high oxidation number of chlorine) and react vigorously with ethers at high temperature and high current ${ }^{[55]}$. The two remaining salts, lithium bis(trifluoromethylsulfonyl)imide (LiTFSI) and lithium bis(pentafluoroethanesulfonyl)imide (LiBETI), are considered to be suitable in ether solvents due to their high ionic conductivity. LiTFSI, however, features a lower viscosity, well-defined temperature stability, optimum donor number, and low cost, which makes it a better option than LiBETI as a Li/S battery salt in ether-based solvents.

LiTFSI, which features a low melting point $\left(234{ }^{\circ} \mathrm{C}\right)$ and very high conductivity $(11 \mathrm{mS} / \mathrm{cm})$ in DOL-DME solution, has a resonance stabilized anion (TFSI $\left.{ }^{-}\right)$. Due to the resonance stabilization, TFSI' anions act as very poor Lewis bases, leading to lower lattice energy and higher ionic conductivity. Thus, LiTFSI can dissociate even in solvents with very low dielectric coefficients ${ }^{[76,77]}$. 
WILEY-VCH<smiles>O=S(=O)(N=S(=O)([O-])C=C1C=CC=C1)N=S(=O)([O-])C(F)(F)F</smiles>

Figure 9 Resonance structure of the TFSI anion ${ }^{[51]}$. Reprinted with permission. Copyright2004, American Chemical Society.

Figure 9 shows the five different stable resonance structures of the TFSI anion, where the negative ions (delocalized electron clouds) continuously shift between the nitrogen and the four oxygen atoms. This resonance stabilization is also triggered by two strongly electronwithdrawing triflic $\left(\mathrm{CF}_{3}\right)$ groups. Hence, the bond between $\mathrm{Li}^{+}$and $\mathrm{TFSI}^{-}$is very labile and dissociates with very little energy ${ }^{[78]}$. Thus, the LiTFSI salt is highly soluble in both protic and aprotic solvents. In protic solutions (e.g., water), LiTFSI can have a solubility as high as $21 \mathrm{~mol} / \mathrm{kg}$ (molal), and in aprotic solutions (DOL-DME), $7 \mathrm{M}$ (molar) has been reported so far ${ }^{[79,80]}$. The low lattice energy and dissociation energy of LiTFSI creates a new electrolyte system, commonly known as concentrated electrolyte or "salt in solvent" electrolyte.

It is important to mention here that the solubility of polysulfides sharply drops with decreasing polysulfide chain length. This has been elaborately described by Pan et al. ${ }^{[81,82]}$ in their Li-S redox flow battery system. They also found that $\mathrm{L}_{2} \mathrm{~S}_{4}$ polysulfide shows less than 0.1M solubility in DOL/DME solution, whereas THF and other solvents (e.g. dimethyl sulfo- 


\section{WILEY-VCH}

oxide) show higher solubility. From the above information, it seems that the DOL/DME solvent is not suitable for Li/S battery electrolyte. However, they further observed that, with the addition of stable anion, the solubility of $\mathrm{L}_{2} \mathrm{~S}_{4}$ polysulfide in DOL/DME electrolyte increased drastically. A small amount of LiTFSI salt can increases $\mathrm{Li}_{2} \mathrm{~S}_{4}$ and $\mathrm{Li}_{2} \mathrm{~S}_{2}$ polysulfide significantly.

It can be inferred from the properties of the solvents and salts that a binary mixture of DOL and DME along with the organometallic salt LiTFSI should exhibit better electrolytic properties in $\mathrm{Li} / \mathrm{S}$ systems. For further confirmation, it is necessary to employ the electrolyte in an electrochemical cell and evaluate its performance. Kim et al. ${ }^{[83]}$ recently compared the effects of different salts in DOL-DME solvent on the cycling performance of $\mathrm{Li} / \mathrm{S}$ batteries, and the results are shown in Figure 10. As expected, LiTFSI shows the best cycling performance, specifically the best initial discharge capacity and capacity retention compared to the other salts, due to its high ionic conductivity in DOL-DME solvent and its highest donor number. These two properties are determined by the anionic stability of the salt and the compatibility between the salts and solvents. In both cases, LiTFSI shows promising features due to the five different resonance structures of TFSI. LiBETI, which also possesses a stable anion, shows promising capacity but is impaired by its high viscosity and cost. On the other hand, $\mathrm{LiPF}_{6}$ and lithium triflate (LiTf) are not well-suited to DOL-DME solvent and also have low donor numbers. 


\section{WILEY-VCH}

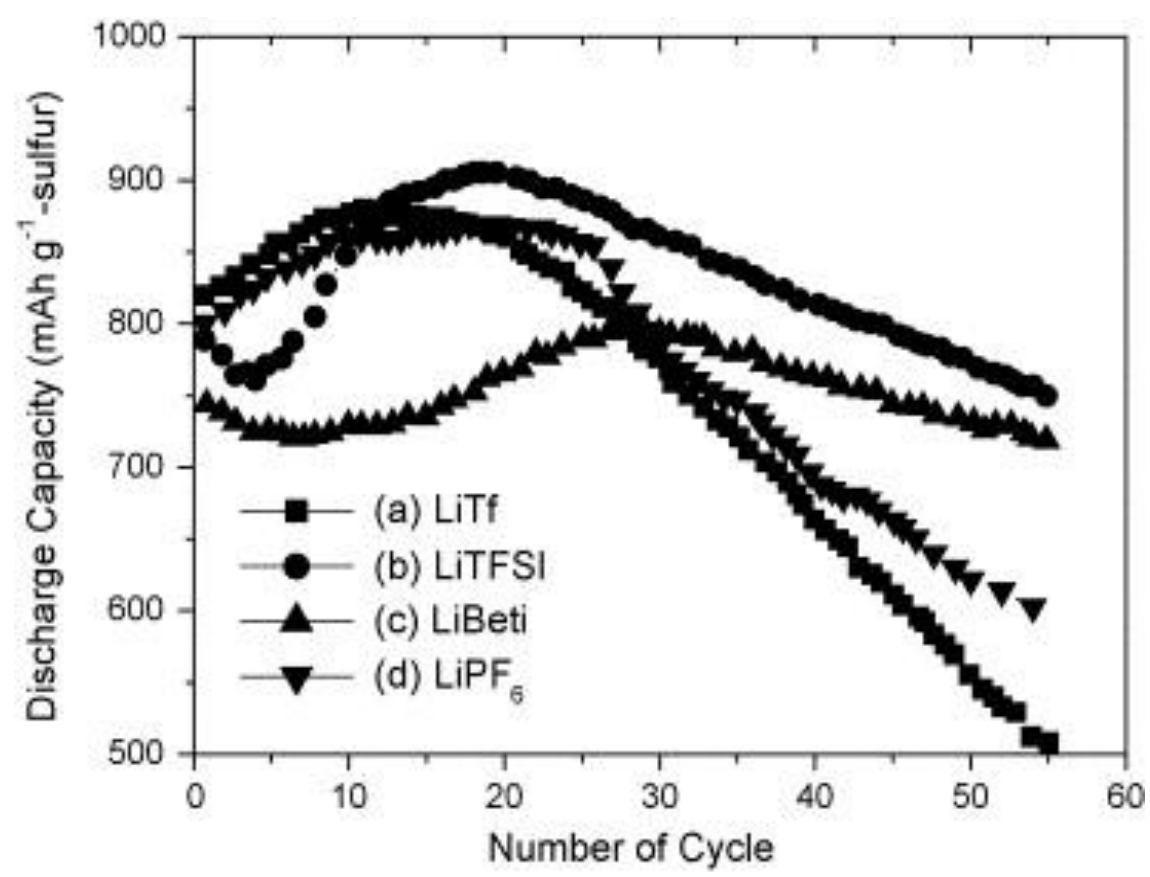

Figure 10 Cycling performance of Li/S cells containing a DOL/DME solvent mixture with a $1 \mathrm{M}$ salt concentration ${ }^{[74]}$. Reprinted with permission. Copyright-2007, Elsevier.

Cao et al. ${ }^{[84]}$ investigated the anionic activity of Li-salts towards the stability of the lithium metal anode in the Li/S battery. They used equimolar DOL/DME as the solvent and LiTFSI and lithium bis(fluorosulfonyl)imide (LiFSI) as the salts with a concentration of $3 \mathrm{M}$ and observed the cycling performance. The cycling performance, presented in Figure 11, of the LiTFSI-containing electrolyte shows a high specific capacity and high capacity retention, even after 200 cycles, whereas the cell with the LiFSI-containing electrolyte was unable to achieve high capacity and exhibited very low capacity retention, even after forty cycles. They finally concluded that the N-S bond in the $\mathrm{FSI}^{-}$anion is the weakest, and its breakage could lead to the formation of lithium sulfate $\left(\mathrm{LiSO}_{x}\right)$ in the presence of polysulfide. The continuous breakage of the N-S bond will induce the fast growth of insulating lithium sulfate passivation layers, along with other complexes. On the other hand, the C-S bond in the $\mathrm{TFSI}^{-}$anion is much stronger compared to the N-S bond in the $\mathrm{FSI}^{-}$anion, and hence, breakage of the $\mathrm{C}-\mathrm{S}$ bond in the $\mathrm{TFSI}^{-}$anion is unlikely; furthermore, even if it does break, it leads to the formation of lithium sulfide $\left(\operatorname{LiS}_{x}\right)$ in the presence of soluble polysulfide. They also stated that 


\section{WILEY-VCH}

the diffusion coefficient of $\mathrm{FSI}^{-}$anions $\left(D_{\mathrm{FSI}}\right)$ in $3 \mathrm{M} \mathrm{LiFSI-DME/DOL} \mathrm{is} \mathrm{clearly} \mathrm{larger} \mathrm{than}$ the measured value for $\mathrm{Li}\left(D_{\mathrm{FSI}}>D_{\mathrm{Li}}\right)$. The diffusion coefficient of $\mathrm{TFSI}^{-}$anions in $3 \mathrm{M}$ LiTFSI-DME/DOL, however, is similar to that of $\mathrm{Li}^{+}\left(D_{\mathrm{TFSI}} \approx D_{\mathrm{Li}}\right)$. The higher diffusion coefficient of $\mathrm{FSI}^{-}$anions generally reflects weaker coordination by the solvent molecules, which may accelerate their decomposition on the surface of the Li metal anode, leading to a greater extent of polysulfide shuttling.
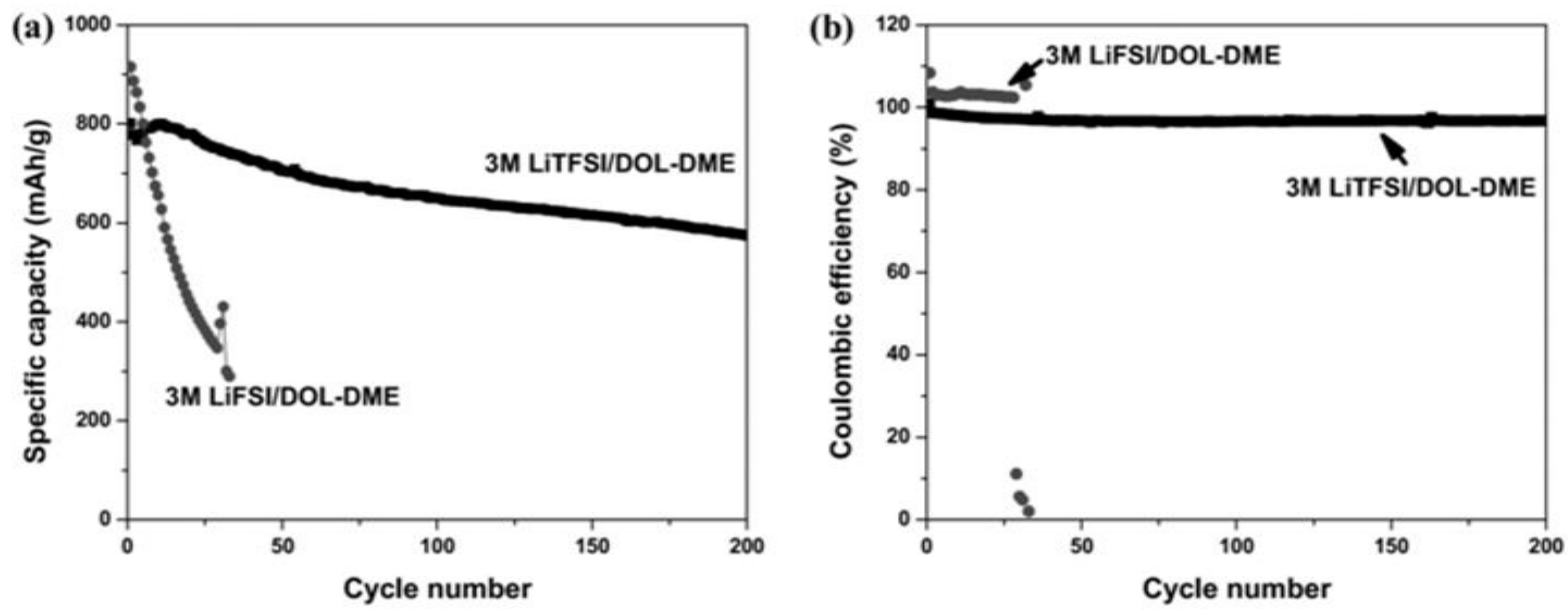

Figure 11 a) Cycling stability and b) coulombic efficiency of Li-S batteries with 3 M LiTFSI and 3 M LiFSI in DOL-DME (1:1 by volume) ${ }^{[74]}$. Reprinted with permission. Copyright 2016, Wiley.

Another important characteristic for LiTFSI salt in DOL/DME solvent has been observed by Suo et al. He found that highly concentrated LiTFSI salt in DOL/DME (later, he named it solvent-in-salt electrolyte) exhibits better electrochemical performance compared to its low concentration electrolyte. He demonstrated that this concentrated electrolyte can not only inhibit the polysulfide dissolution phenomenon but also can effectively protect the metallic lithium anode against the formation of lithium dendrites ${ }^{[80]}$. Figure 12 shows that 7 M LiTFSI in DOL/DME solvent not only exhibits a higher discharge capacity compared to $2 \mathrm{M}$ and $4 \mathrm{M}$ electrolyte but also shows very high rate capability and better Coulombic efficiency. 


\section{WILEY-VCH}
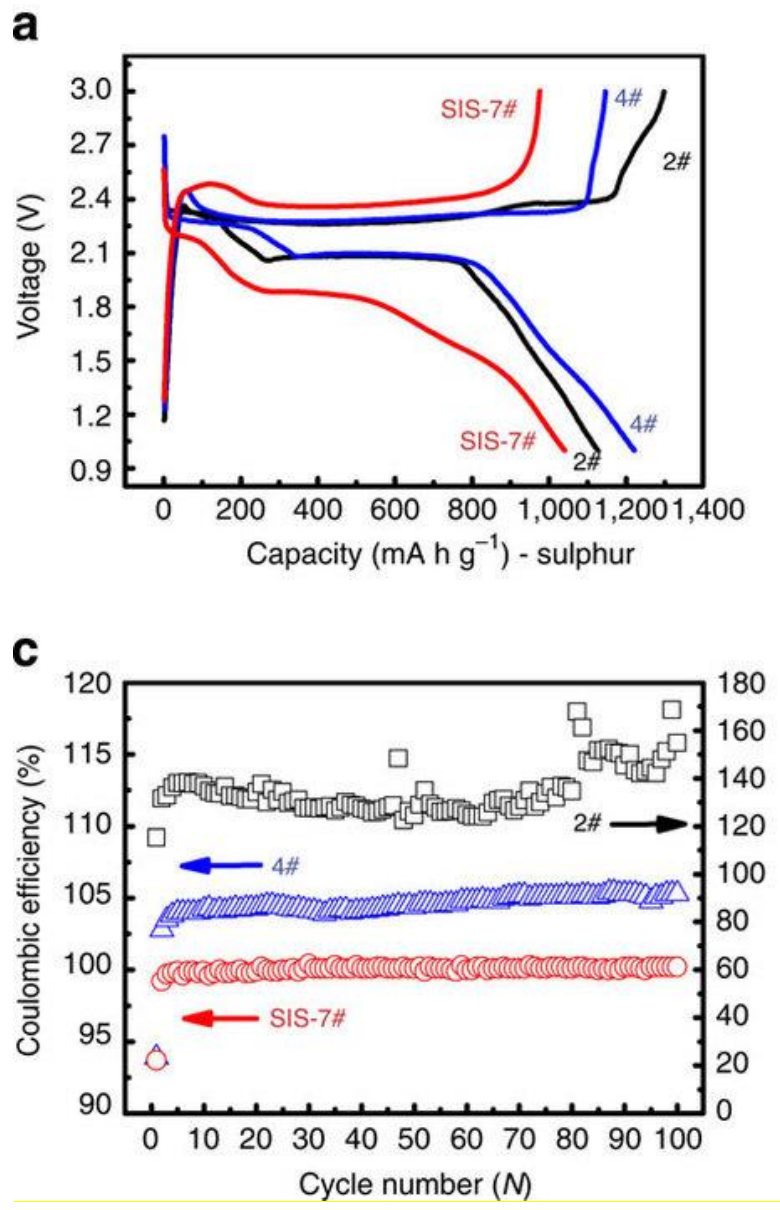

b

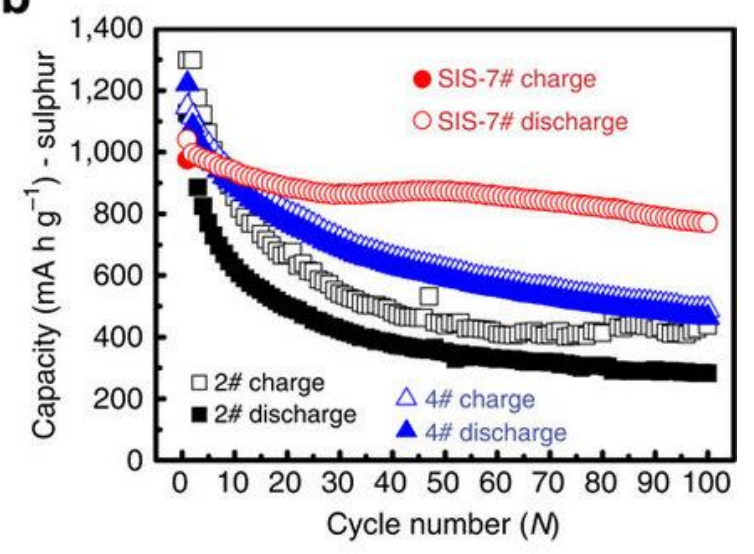

d

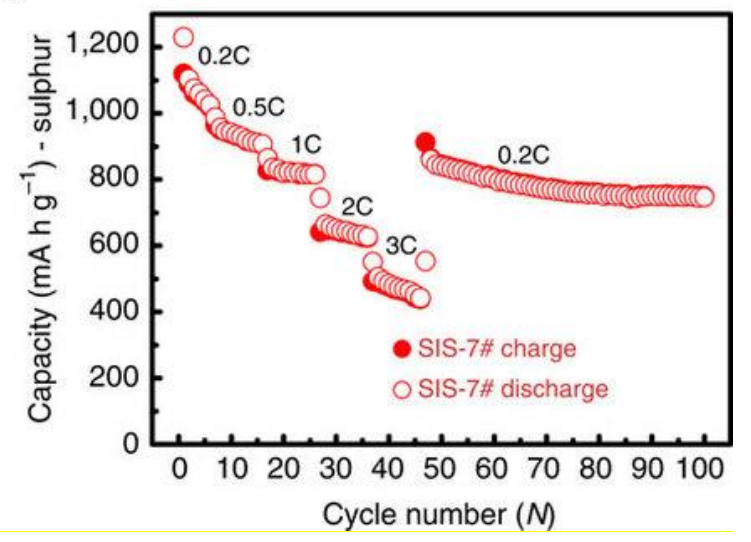

Figure 12 a) First discharge-charge profiles of $\mathrm{C} / \mathrm{S}$ electrodes in electrolytes with different ratios of LiTFSI to DOL:DME (1:1 by volume). b) Cyclic performance. c) Coulombic efficiency at a current rate of 0.2 C. d) Rate capability with 7M LiTFSI electrolyte. Reprinted with permission. Copyright 2013, Nature communication.

Transportation of ions, another important characteristics of electrolyte, has been briefly discussed in this section. The weakly coordinated lithium ion-based salts release lithium ion when solvated in solvent. During charging and discharging these ions move back and forth in between electrodes. The numbe of ions transported between the electrodes and their speed determine the energy and power of a battery. The ability to transfer a higher number of ions with greater speed between electrodes is also one of the key criteria for a suitable electrolyte. Ion transport between electrodes generally occurs in three ways: migration, convection, and diffusion ${ }^{[55]}$. Among them, migration and diffusion are the major transport means; however, 


\section{WILEY-VCH}

ions in the electrolyte that are transported through convection are coordinated with electrolyte molecules and are driven to the counter electrode by an electric field. The speed of the ions have a significant impact on the energy and power of a cell.

$$
v=1 /(6 \pi \eta r)
$$

The ion mobility is heavily dependent on the electrolyte, specifically the structure of the solvent and the viscosity of the electrolyte, which depend not only on the solvent structure but also on the salt. Eq. (4), the Stokes-Einstein equation, determines the velocity of the ions. In Equation (4), $\eta$ represents the viscosity of the electrolyte, $r$ represents the solvation radius, and $v$ represents the ion mobility. The equation states that the ion mobility is inversely proportional to the viscosity and the solvation radius. Again, the viscosity and the solvation radius are functions of the solvents and salts. Solvents and salts that have high molecular weights and larger sizes show high viscosity and hence reduced ion mobility. Therefore, TEGDME/DOL has a lower ionic conductivity than DOL/DME.

\section{Additives and formation of a solid electrolyte interphase (SEI) for Li/S batteries}

From a thermodynamic point of view, electrolytes and salts should have an electrochemical stability window (energy gap between the highest occupied molecular orbital and the lowest unoccupied molecular orbital) that is beyond the oxidation and reduction potentials of the anode and cathode, respectively. The Li/S system, where Li metal is used as the anode, has a reduction potential of $-3.04 \mathrm{~V}$ (vs. the standard hydrogen potential), which is higher than the lowest unoccupied molecular orbital energy of most aprotic electrolytes. Thus, the electrolyte should continuously decompose when the potential of the electrode passes beyond the electrochemical stability window. However, electrolytes have been shown to decompose and form an SEI layer on the lithium surface, which prevents further decomposition of the electrolyte $^{[85]}$. In the Li/S system, when DOL/DME with LiTFSI salt is used as the electrolyte, 


\section{WILEY-VCH}

an SEI is formed on the Li anode by the decomposition of DOL and LiTFSI ${ }^{[86]}$. The exact mechanism for the formation of the SEI is yet to be discovered, although it has been hypothesized that a thin layer of lithium complexes $\left(\mathrm{LiOR}, \mathrm{HCO}_{2} \mathrm{Li}, \mathrm{Li}_{2} \mathrm{NSO}_{2} \mathrm{CF}_{3}, \mathrm{Li}_{2} \mathrm{SO}_{2} \mathrm{CF}_{3}\right.$ and $\mathrm{Li}_{x} \mathrm{CF}_{y}$ ) derived through reactions of DOL, LiTFSI, and lithium ${ }^{[85]}$ comprise the thin SEI layer. However, due to the infinitive volume change of the $\mathrm{Li}$ anode during $\mathrm{Li}$ deposition/depletion, this thin SEI layer cannot completely prevent further decomposition of the electrolyte during cycling.

As mentioned earlier, the Li/S battery suffers from several notable challenges, and among them, the shuttle phenomenon, where longer chain polysulfides react with lithium and are reduced to shorter chain polysulfides, is the most notorious. The thin SEI layer that is formed by the decomposition of DOL and LiTFSI fails to prevent polysulfide diffusion to the lithium metal surface, and hence, severe capacity fading occurs in subsequent cycles. Comprehensive research has been conducted to mitigate this challenge, and the use of additives, specifically lithium salts (simple salts), was found to be helpful ${ }^{[10,87,88,89]}$. Among them, $\mathrm{LiNO}_{3}$ results in the most significant improvement in the cycling performance by forming a more stable and thicker SEI layer, which suppresses the shuttle phenomenon ${ }^{[58,90]}$. Aurbach et al. proposed that $\mathrm{LiNO}_{3}$, LiTFSI, and lithium metal react with ether-based electrolyte to form multiple complexes, which are then deposited at the lithium metal-organic electrolyte interface ${ }^{[86]}$. Xiong et al. meticulously studied the SEI formation and characterized its chemical structure. They found not only that $\mathrm{LiNO}_{3}$, LiTFSI, and DOL are responsible for SEI formation but also that polysulfides play a critical role in thickening the SEI layer ${ }^{[89,91,92]}$. They proposed that long-chain polysulfides $\left(\mathrm{Li}_{2} \mathrm{~S}_{8}, \mathrm{Li}_{2} \mathrm{~S}_{6}\right.$, and $\left.\mathrm{Li}_{2} \mathrm{~S}_{4}\right)$ dissolve during the first discharge, are reduced to short-chain polysulfides $\left(\mathrm{Li}_{2} \mathrm{~S}_{2}\right.$ and $\left.\mathrm{Li}_{2} \mathrm{~S}\right)$, and are deposited on the lithium metal surface along with the reduced product of $\mathrm{LiNO}_{3}\left(\mathrm{LiN}_{x} \mathrm{O}_{y}\right)^{[91,92]}$. Another layer is also deposited on top of this layer, which consists of lithium sulfate and lithium thiosulfate formed 


\section{WILEY-VCH}

through oxidation of the polysulfides (Figure 13). They also inferred that this top layer is much more stable and prevents direct contact between the electrolyte and the fresh lithium surface, which helps reduce the shuttle phenomenon ${ }^{[93]}$. A schematic illustration of their proposed SEI formation mechanism is shown below.

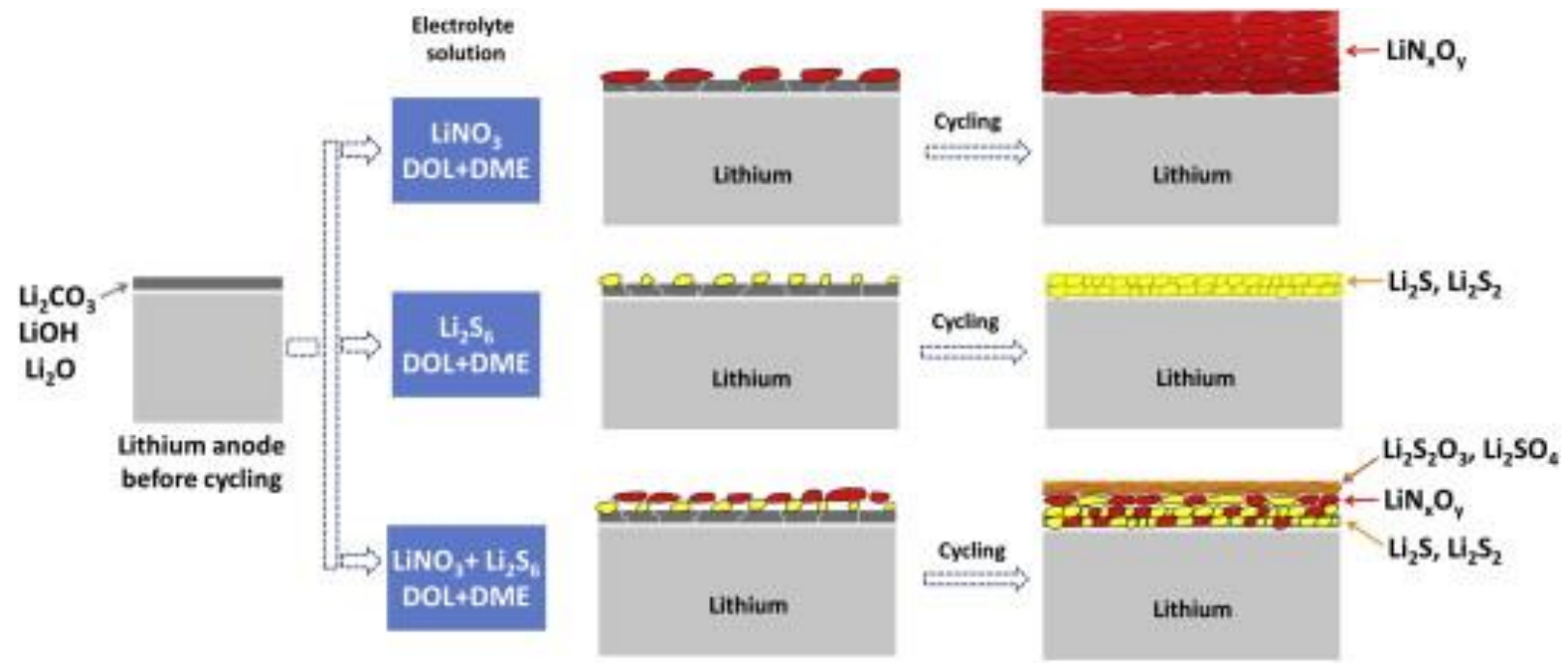

Figure 13 Effects of $\mathrm{LiNO}_{3}$ and polysulfides on the formation of the SEI ${ }^{[81]}$. Reprinted with permission. Copyright 2012, Elsevier.

The effects of $\mathrm{LiNO}_{3}$ on the electrochemical performance have been studied by several researchers $[59,94,95]$. Among them, Xin et al. studied the effects of $\mathrm{LiNO}_{3}$ on the coulombic efficiency of a polypyrrole-coated sulfur electrode. They found that with the addition of $0.1 \mathrm{M}$ $\mathrm{LiNO}_{3}, 100 \%$ of the coulombic efficiency was retained, even after fifty cycles (Figure 14), and they concluded that a small amount of $\mathrm{LiNO}_{3}$ can form a dense and stable SEI, which successfully prevents the reduction of longer chain polysulfides, hence alleviating the shuttle phenomenon. 
WILEY-VCH

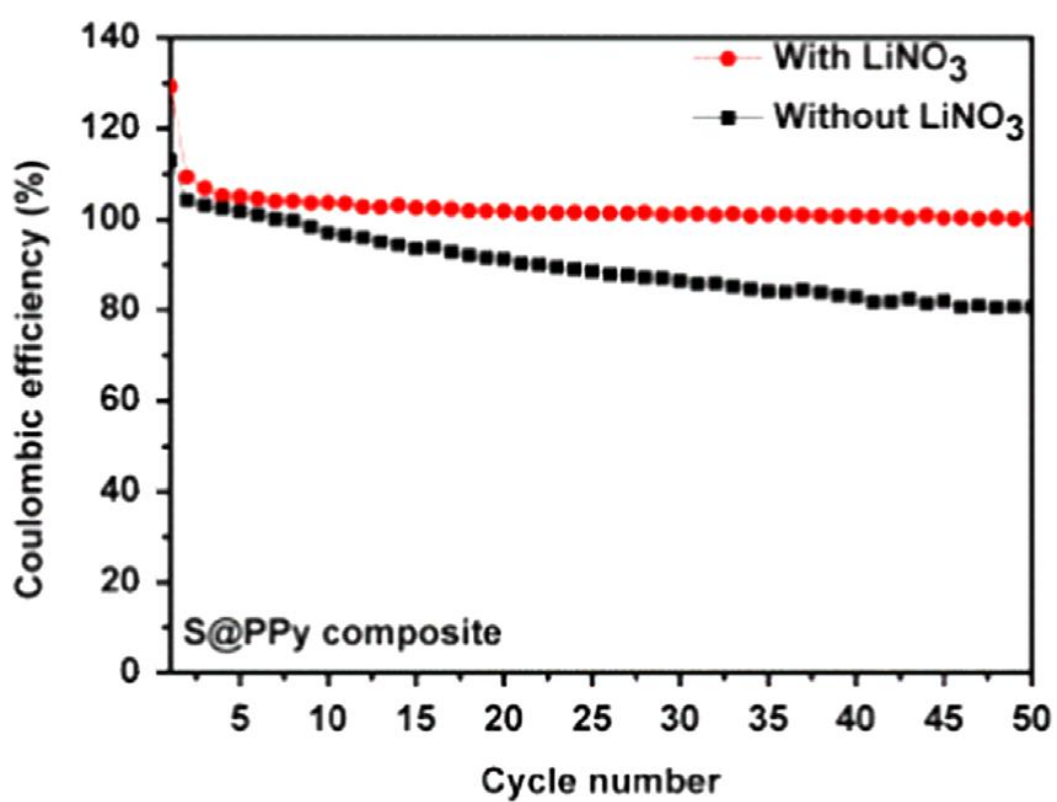

Figure 14 Effect of $\mathrm{LiNO}_{3}$ on the coulombic efficiency of a polypyrrole-coated sulfur cathode

[55]. Reprinted with permission. Copyright 2015, Elsevier.

\section{Application of DOL/DME-LiTFSI-based electrolyte in Li/S batteries}

Thus far, it has been well established that DOL/DME and LiTFSI-based electrolyte with $\mathrm{LiNO}_{3}$ additive possesses better electrochemical performance than alternative electrolytes. A short survey of the Web of Science was conducted regarding number of papers published on $\mathrm{Li} / \mathrm{S}$ batteries in 2016. Among the 553 papers published in 2016, more than $92 \%$ used DOL/DEM and LiTFSI electrolyte in their $\mathrm{Li} / \mathrm{S}$ system, with most using $\mathrm{LiNO}_{3}$ as an additive in the electrolyte. A few recent works that have been published in high-impact journals, where DOL/DME and LiTFSI-based electrolyte was used along with a modified cathode and separator, are presented below, with details on their electrochemical performances. 
WILEY-VCH
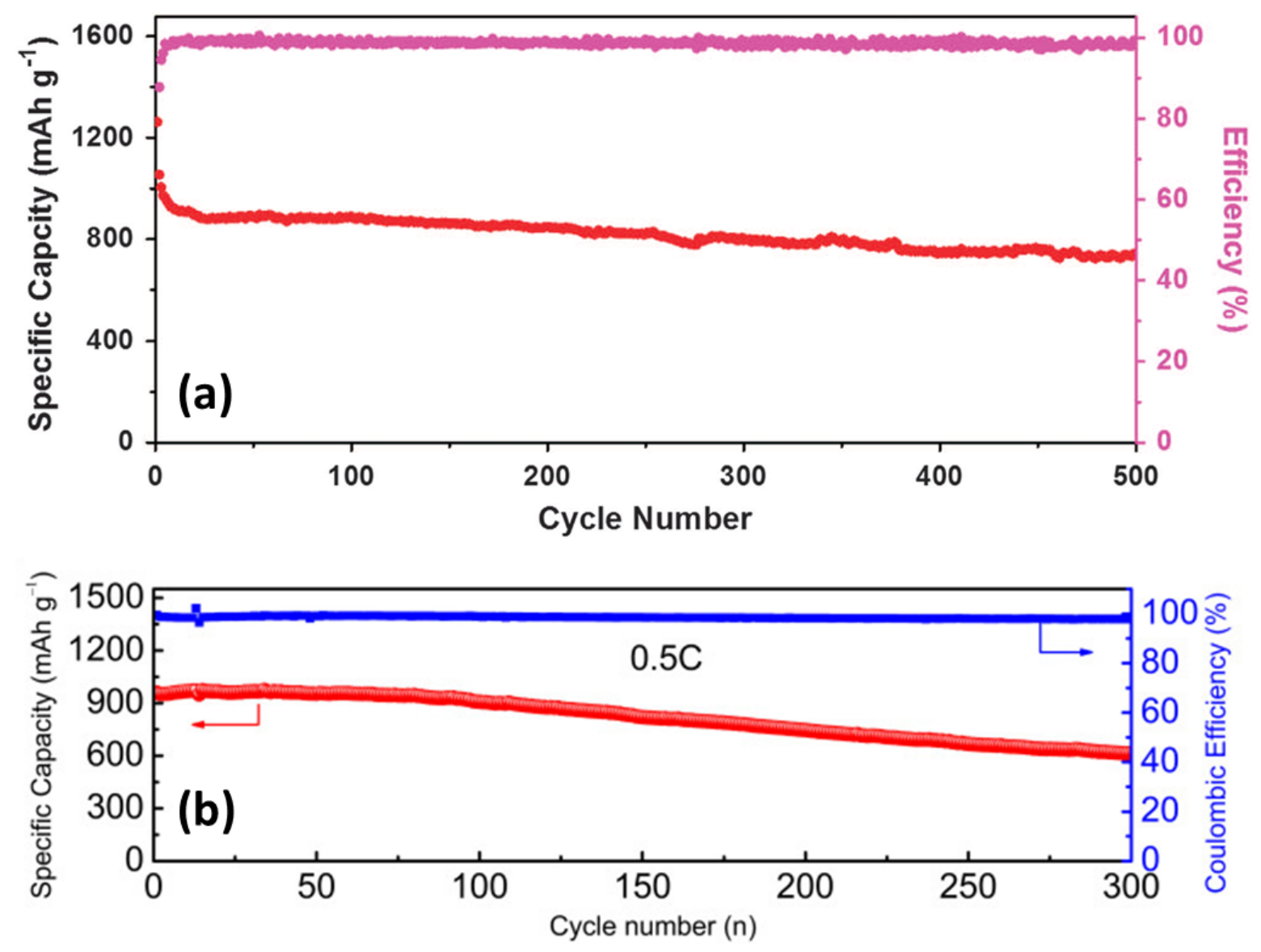

Figure 15 Electrochemical performance of Li/S systems where DOL/DME and LiTFSI electrolyte and $\mathrm{LiNO}_{3}$ additive were used with a) a polybenzimidazole binder ${ }^{[96]}$ and b) carbon nanotubes (CNTs) and activated carbon nanofibers (ACNFs) in an $\mathrm{MnO}_{2}$ host ${ }^{[97]}$.

Reprinted with permission. Copyright 2016, NPG and Elsevier.

Figure $15 \mathrm{a}$ and $15 \mathrm{~b}$ shows the discharge capacity of two different $\mathrm{Li} / \mathrm{S}$ cells that used DOL/DME and LiTFSI electrolyte with $\mathrm{LiNO}_{3}$ additive. The only difference was in the fabrication of the cathode, where a polybenzimidazole binder was used in Figure 15a and a combination of different conductive carbons was used in Figure 15b. In both cases, the discharge capacity remained stable, even after several hundred cycles, and a very high coulombic efficiency was achieved, which is only possible by using the best combination of solvents, salts, and additives in the electrolyte. 


\section{WILEY-VCH}
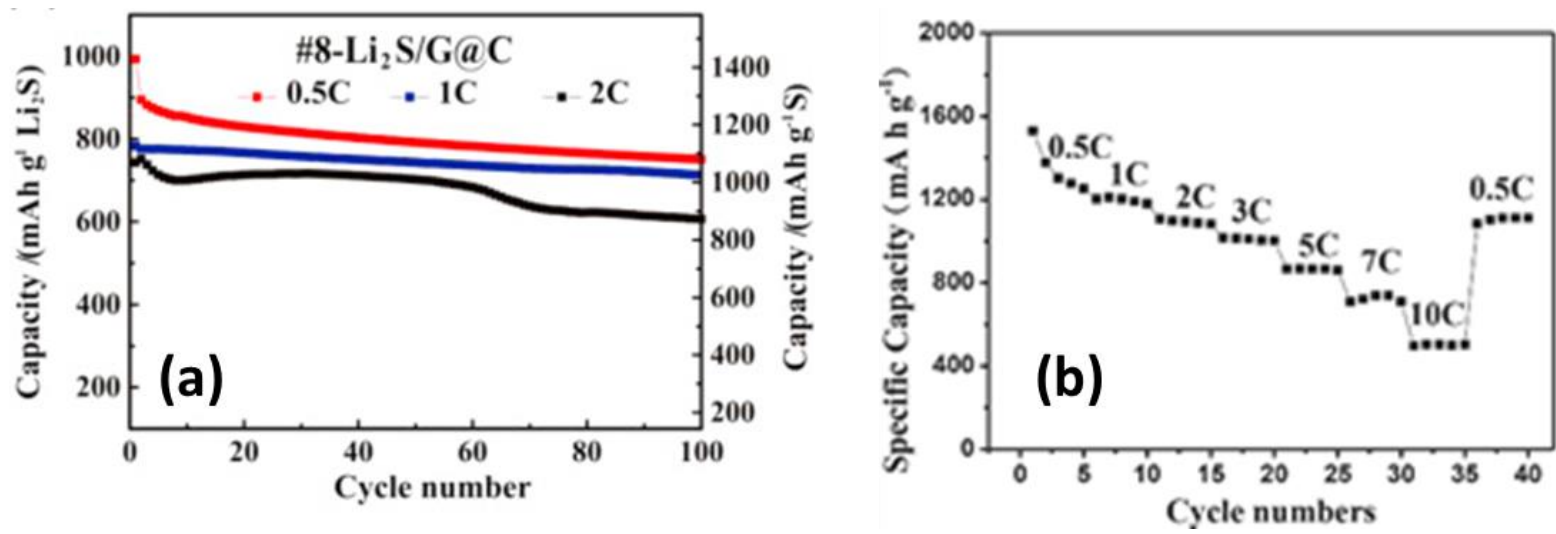

Figure 16 Electrochemical performance of an Li/S system containing a DOL/DME, LiTFSI, and $\mathrm{LiNO}_{3}$ electrolyte system and a) a graphene/ $\mathrm{Li}_{2} \mathrm{~S}$ cathode ${ }^{[98]}$ or b) a sandwich -type hybrid carbon nanosheet (SCNMM)/sulfur cathode ${ }^{[99]}$. Reprinted with permission. Copyright 2016 Elsevier and 2014 Wiley.

Similar to Figure 15, Figure 16 also shows the electrochemical performance of a $\mathrm{Li} / \mathrm{S}$ system containing a DOL/DME, LiTFSI, and $\mathrm{LiNO}_{3}$ electrolyte system along with two modified sulfur cathodes. In Figure 16a, lithiated sulfur anchored in single-layer graphene was used instead of the conventional sulfur/carbon composite cathode. Alternatively, a sandwich-type hybrid carbon nanosheet and sulfur composite was applied in Figure 16b. In both cases, a high and stable discharge capacity was achieved, even at very high current density. It has been accepted by the scientific community that a high electrochemical performance can never be achieved by solely modifying the electrodes, specifically the cathode, unless a suitable electrolyte is employed.

\section{Carbonate-based electrolyte with a short-chain sulfur-based cathode for $\mathrm{Li} / \mathrm{S}$ systems}

As discussed earlier, even though carbonate-based electrolytes show better physiochemical properties and have been used in Li-ion batteries for the last two decades, they are not suitable for $\mathrm{Li} / \mathrm{S}$ systems due to the irreversible reactions that occur between polysulfides and carbonates. The proposed mechanism and reaction products are shown in Figure 4. It was 


\section{WILEY-VCH}

previously established that carbonate-based electrolytes are unsuitable for $\mathrm{Li} / \mathrm{S}$ systems; however, in 2010, Gao et al. ${ }^{[48]}$ reported that carbonate-based electrolytes (EC, PC, and DEC) together with $\mathrm{LiPF}_{6}$ salt can be used in $\mathrm{Li} / \mathrm{S}$ batteries, but only if the sulfur particles are homogeneously dispersed inside the micropores of carbon spheres. Later, different approaches ${ }^{[100,101,102,103]}$ were adopted to use carbonate-based electrolyte, in which different carbon sources were used instead of microporous carbon. Gentle et al. ${ }^{[100]}$ used a hierarchy of micropores and mesopores, and Wang et al. ${ }^{[104]}$ impregnated disordered carbon nanofibers with sulfur, making them compatible with carbonate-based electrolytes. Both groups successfully used carbonate electrolytes, although the mechanism at the molecular level was not explained.

Few hypotheses regarding the mechanisms involved in the use of carbonate-based electrolytes have been well-accepted by the scientific community, namely, the formation of special complexes, the desolvation of solvated lithium ions in micropores, and the assimilation of short-chain sulfurs in micropores ${ }^{[105]}$. Among them, the latter approach is favored by most researchers. Wang et al. have claimed that at high temperature or in solution, short-chain sulfurs $\left(\mathrm{S}_{4}, \mathrm{~S}_{2}\right.$, etc. $)$ can easily be impregnated into micropores due to their simple and linear molecular structure, and during discharge, they react with lithium to form short-chain polysulfides, which are nonreactive to carbonate-based electrolytes. The single plateau discharge curve and stable cycling performance, as shown in Figure 17, strengthen this claim. The conventional two-plateau discharge curve of Li/S systems, where the first plateau results from the formation of longer chain polysulfides $\left(\mathrm{Li}_{2} \mathrm{~S}_{8}, \mathrm{Li}_{2} \mathrm{~S}_{6}\right)$, is absent in this case, which also supports the claim that small-chain sulfurs are confined in the micropores. In addition, the exceptional cycling stability, shown in Figure 17, also supports the claim that there are no longer chain polysulfides, which are mainly responsible for the abrupt capacity decay with

cycle number due to the polysulfide shuttle phenomenon. Very recently, Aurbach et al. ${ }^{[105]}$ 


\section{WILEY-VCH}

claimed that porous carbon, with a pore size of $2-3 \mathrm{~nm}$, can not only accommodate shortchain sulfur but can also accommodate long-chain sulfur or octasulfur ( $\mathrm{S}_{5}$ to $\left.\mathrm{S}_{8}\right)$ and also exhibits the same discharge plateau behavior, which invalidates the proposed effect of the confinement of small-chain sulfurs in the microporous carbon.
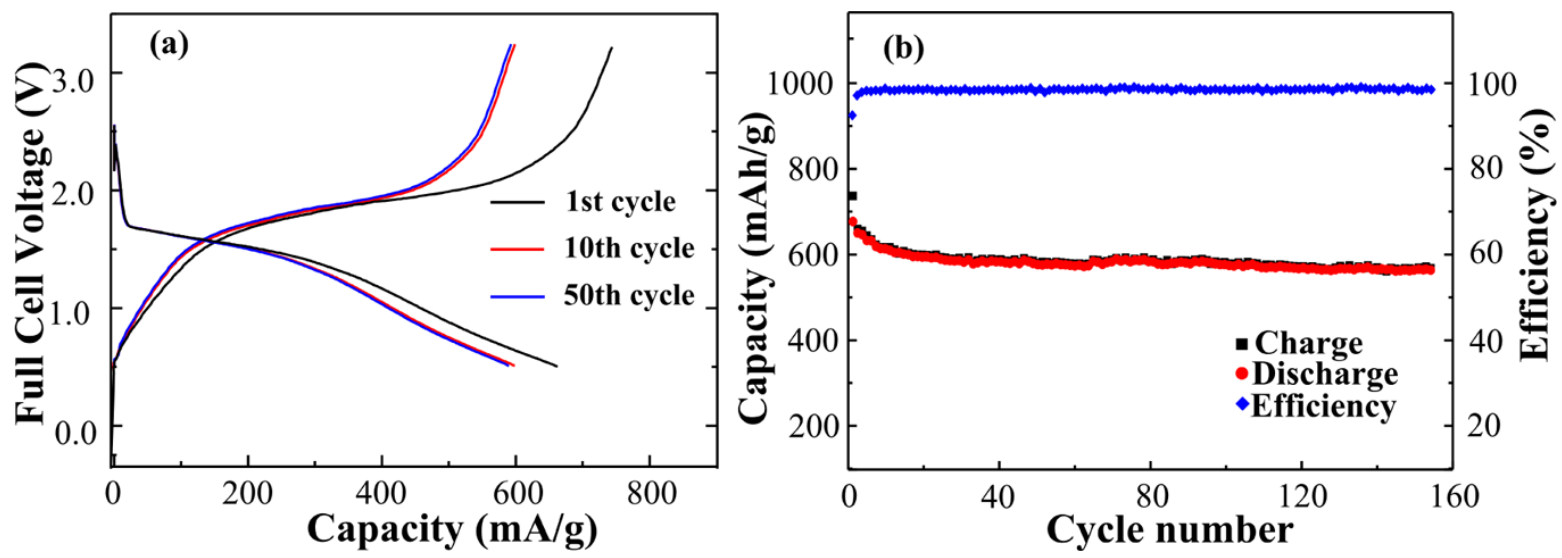

Figure 17 (a) Charge-discharge curve and (b) cycling performance of a sulfur-impregnated microporous carbon cathode ${ }^{[106]}$. Reprinted with permission. Copyright 2013, American Chemical Society.

Aurbach et al. ${ }^{[105]}$ also claimed that the formation of an SEI on the sulfur cathode through a quasi-solid-state reaction during the initial discharge is responsible for the single plateau discharge curve and higher capacity retention. They found that the initial discharge plateau showed an extremely high discharge capacity compared to that in the second and third cycles, which is due to the irreversible reaction between the carbonate-based electrolyte and the microporous carbon/sulfur composite to form an SEI on the cathode surface. Later, Ishikawa et al. ${ }^{[101]}$ found that this single plateau behavior is found not only with carbonate electrolytes but also with ionic liquid and glyme electrolytes, as shown in Figure 18. They also showed support for the quasi-solid-state reaction behavior, as a high discharge capacity during initial discharge was also observed in each of the electrolytes that they studied. 


\section{WILEY-VCH}

Importantly, even though the use of carbonate-based electrolyte promotes high capacity retention, the discharge capacity is quite low, and the cell voltage is approximately $1.5 \mathrm{~V}$, which will reduce the total energy and power of the battery. Therefore, it can be inferred from the above discussion that carbonate-based electrolyte can only be used in microporous carbon and that the resultant cells still suffer from low energy and power.

a

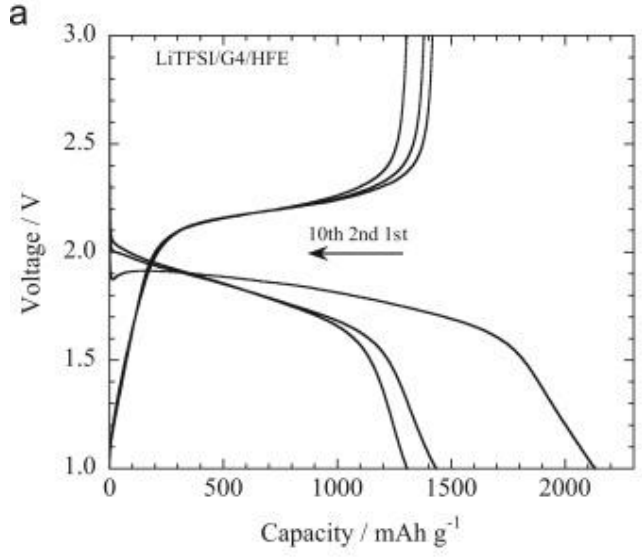

b

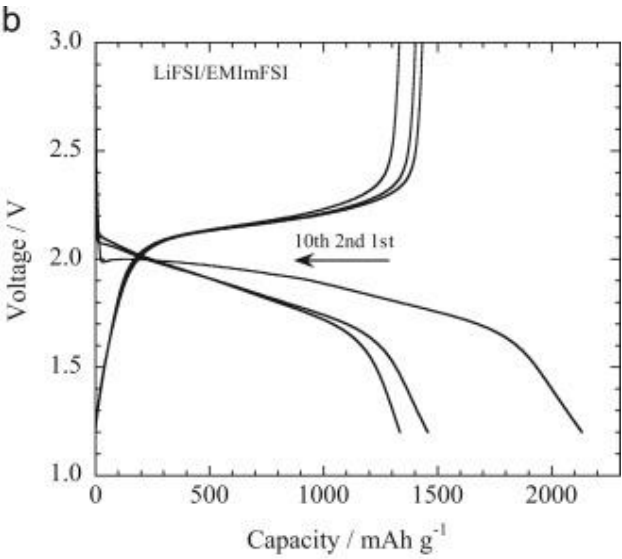

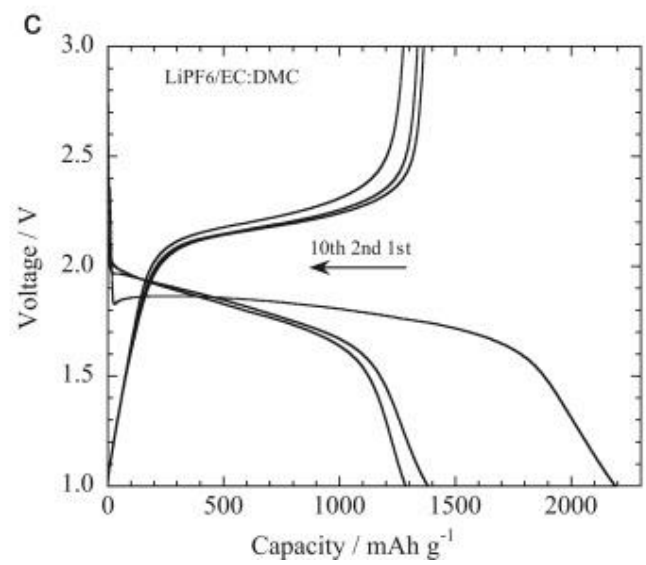

Figure 18 Charge-discharge curves of a sulfur/carbon electrode with (a) LiTFSI/G4/HFE, (b) LiFSI/EMImFSI and (c) LiPF6/EC:DMC electrolyte at $0.1 \mathrm{C}^{[101]}$. Reprinted with permission. Copyright 2015, Elsevier.

\section{Fluorinated electrolyte system for Li/S battery}

Fluorinated ether-based electrolyte, which is a new kind of solvent for Li-S system was recently introduced by Zhang's group ${ }^{[107]}$ and Wang's group. ${ }^{[108,109]}$. They used different types of linear fluorinated ethers, including bis (2,2,2-trifluoroethyl) ether (BTFE) and 


\section{WILEY-VCH}

1,1,2,2-tetrafluoroethyl-2,2,3,3-tetrafluoropropyl ether (TTE), instead of DME in the

DOL/DME and LiTFSI system. They showed that the fluorinated ether-based solvent can form a stable and thick SEI, as well as reducing polysulfide dissolution. In addition, BTFE can significantly enhance the shelf life of the Li-S system.

(a)
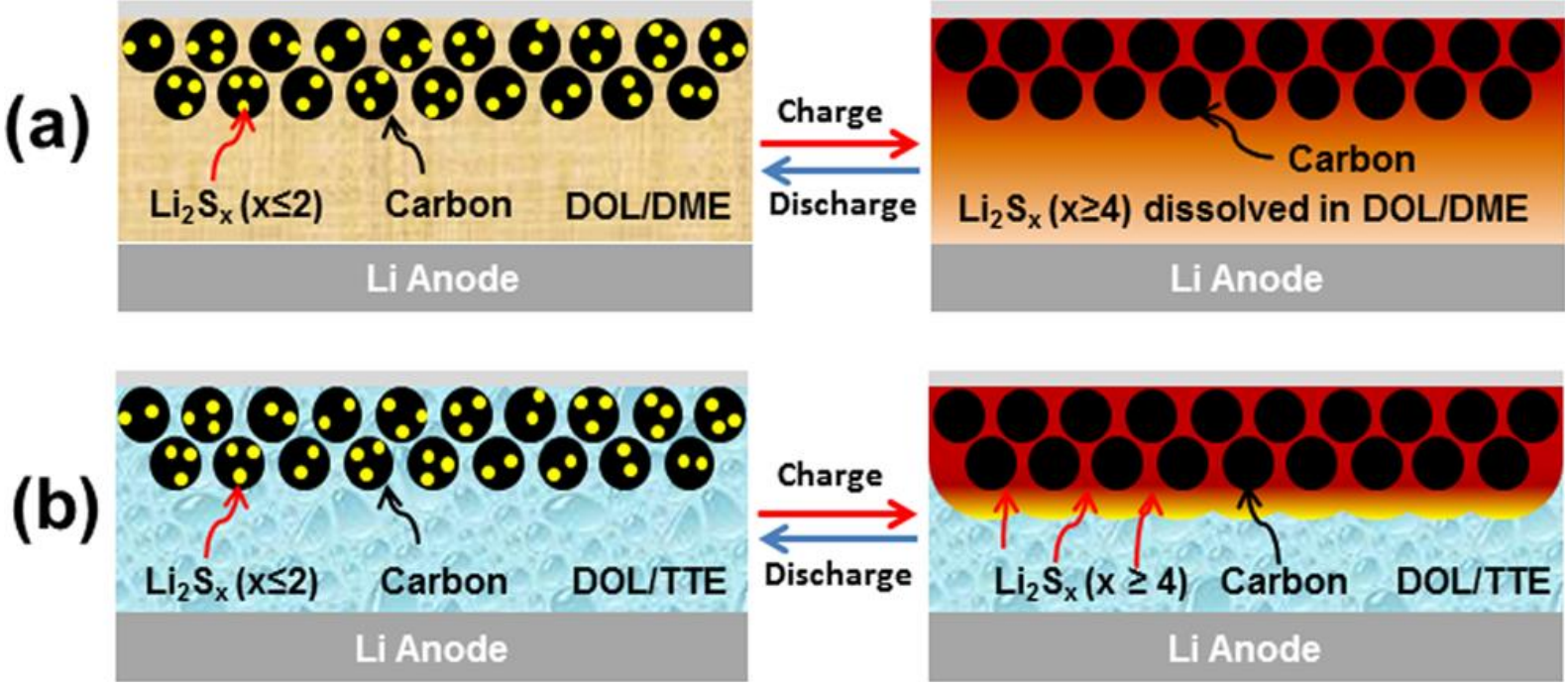

Figure 19 Schematic illustration of (a) the reduction of polysulfide dissolution and (b) the formation of a thick SEI in DOL/TTE electrolyte ${ }^{[107]}$. Reprinted with permission. Copyright 2015, American Chemical Society.

The schematic illustration in Figure 19 shows that long chain polysulfides only have very limited solubility in the DOL/TTE solvent, which decreases the shuttle phenomenon. This new electrolyte system looks promising, but more fundamental work needs to be done, such as determining its ionic conductivity, viscosity, dielectric permittivity, and temperature stability. In addition, a comprehensive DOL-TTE/BTFE phase diagram also needs to be drawn to determine the most appropriate ratio of DOL to the fluorinated ethers.

\section{Conclusions}

In this mini review, we provided an overview of suitable organic electrolytes for $\mathrm{Li} / \mathrm{S}$ systems. Moreover, the effect of the molecular structure on the properties of the solvents and salts in 


\section{WILEY-VCH}

the electrolyte was also demonstrated. Proper selection of solvents, salts, and additives can significantly abate the challenges of $\mathrm{Li} / \mathrm{S}$ batteries. However, these challenges are yet to be solved completely. The dissolution of elemental sulfur and longer chain polysulfides are indispensable and inevitable in Li/S systems. Since sulfur and its polysulfides are insulating in nature, polysulfide dissolved in the electrolyte (or catholyte) can effectively increase the active material utilization and enhance the redox reaction rate. However, highly soluble electrolyte suffers from the shuttle phenomenon due to the induced concentration gradient. Many researchers have inferred that manipulation of the solubility of polysulfide, with either controlled increases or decreases, can solve the challenges of $\mathrm{Li} / \mathrm{S}$ systems. Concentrated electrolyte may successfully minimize the shuttle phenomenon by reducing the polysulfide solubility but can result in low ionic mobility and hence, low rate capability. If the lithium ion mobility and the transference number can successfully be improved in such concentrated electrolytes or ionic liquids, which also have appreciable polysulfide solubility, which increases the reaction rate and active material utilization, it is possible to mitigate all the challenges of Li/S systems. A mixture of DOL/DME solvents along with LiTFSI salt has been proven to be effective for ion transport, the dissolution of sulfur and polysulfides, the formation of a suitable SEI layer and the utilization of high amount active material by formation of stable $\mathrm{S}_{3}{ }^{{ }^{*}-}$ radicals. The anionic stability of the LiTFSI salt and the reaction products of DOL and lithium increase the ionic conductivity and contribute to the thickness of the SEI layer, respectively. An additive salt, such as $\mathrm{LiNO}_{3}$, can also significantly reduce the shuttle phenomenon and increase the coulombic efficiency through the formation of a stable and dense SEI layer. Though the combination of DOL/DME, LiTFSI, and $\mathrm{LiNO}_{3}$ is currently the best electrolyte for the Li/S system, a few vital concerns remain. The high reactivity of $\mathrm{LiNO}_{3}$ and the high flammability of DOL/DME impede the commercialization of $\mathrm{Li} / \mathrm{S}$ batteries. In addition, the cycling stability is another area of concern that can be mitigated by additives in this electrolyte system. Moreover, the amount of electrolyte also plays an 


\section{WILEY-VCH}

important role in the electrochemical performance of Li-S system. The dissolution of polysulfides largely depends on the electrolyte to sulfur ratio ${ }^{[110]}$. Comprehensive research should be conducted in DOL/DME and LiTFSI electrolyte systems to find out the electrolyte to sulfur ratio. The ongoing search for additives, salts, and solvents will surely resolve all the challenges of Li/S systems. We believe, however, that the solution lies in the electrolyte rather than in cathodic and anodic modifications of the Li/S system.

\section{Acknowledgements}

The authors gratefully acknowledge the financial support provided by the Automotive Cooperative Research Centre (AUTO CRC 2020) and an Australian Research Council (ARC) Linkage Project (LP 160100914). The authors also thank Fang Li and Dr. Tania Silver for providing the schematic illustrations and a critical reading of the manuscript, respectively.

\section{Author Biographies:}

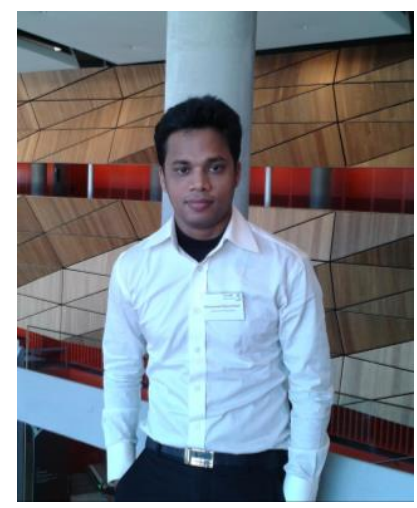

Mohammad Rejaul Kaiser is a doctoral student at the Institute for Superconducting and Electronic Materials (ISEM) at the University of Wollongong under Prof. Jiazhao Wang. He was also a visiting PhD student at the University of Maryland, USA, in Prof. Chunsheng Wang's group from November 2015 to September 2016. His research focuses on "Rechargeable Li/S Batteries" and is funded by Excellerate Australia. He holds an MSc in Materials Engineering from the International Islamic University, Malaysia, where he was employed as a research assistant for one year and studied polymer biocomposites. He was employed as an Assistant Engineer in AKSPL, Bangladesh, after completing his BSc in Materials Engineering from BUET, Bangladesh. 


\section{WILEY-VCH}

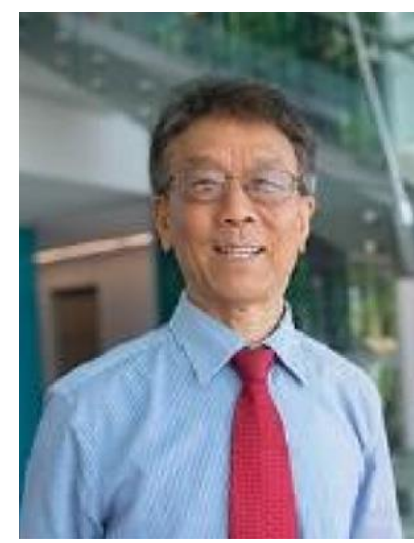

Shi-Xue Dou is a Distinguished Professor at the University of Wollongong. He received his PhD in chemistry in 1984 at Dalhousie University, Canada, and his DSc at the University of New South Wales in 1998. He was elected as a Fellow of the Australian Academy of Technological Science and Engineering in 1994. He was awarded the Australian Government's Centenary Medal in 2003, as well as multiple Australian Professorial Fellowships. He has supervised $85 \mathrm{PhD}$ students and more than 50 postdoctoral and visiting fellows.

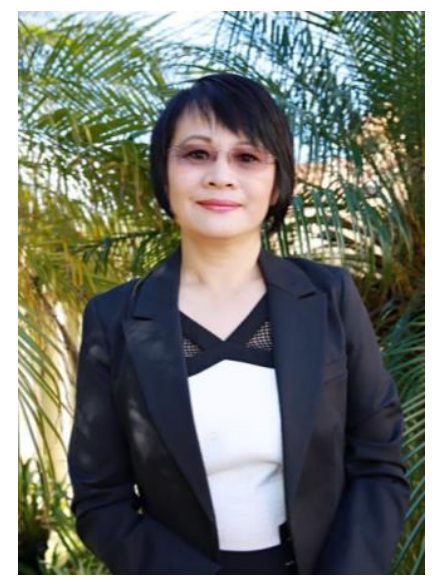

Jiazhao Wang is a Professor at the Institute for Superconducting and Electronic Materials (ISEM), University of Wollongong (UOW), Australia. She obtained her $\mathrm{PhD}$ from the University of Wollongong in 2003. She has successfully applied for five competitive Australian Research Council (ARC) Projects as a team leader between 2009-2016. Her research focuses on the design, synthesis and characterization of new materials for energy applications, including lithium-ion batteries, lithium-sulfur batteries, lithium air batteries, and sodium batteries.

\section{References}

[1] P. G. Bruce, S. A. Freunberger, L. J. Hardwick, J.-M. Tarascon, Nat Mater 2012, 11, 19.

[2] M. Armand, J. M. Tarascon, Nature 2008, 451, 652.

[3] Y. M. Chiang, Science 2010, 330, 1485.

[4] S. S. Zhang, J Power Sources 2013, 231, 153.

[5] S. Zhang, K. Ueno, K. Dokko, M. Watanabe, Advanced Energy Materials 2015, 5, n/a.

[6] A. Manthiram, Y. Fu, Y.-S. Su, Accounts of Chemical Research 2013, 46, 1125.

[7] J. Zheng, M. Gu, M. J. Wagner, K. A. Hays, X. Li, P. Zuo, C. Wang, J.-G. Zhang, J. Liu, J. Xiao, J Electrochem Soc 2013, 160, A1624. 


\section{WILEY-VCH}

[8] A. Manthiram, Y. Fu, S.-H. Chung, C. Zu, Y.-S. Su, Chemical Reviews 2014.

[9] M. Wild, L. O'Neill, T. Zhang, R. Purkayastha, G. Minton, M. Marinescu, G. J. Offer, Energ Environ Sci 2015, 8, 3477.

[10] J. Scheers, S. Fantini, P. Johansson, J Power Sources 2014, 255, 204.

[11] R. Xu, J. Lu, K. Amine, Advanced Energy Materials 2015, 5, n/a.

[12] D. Larcher, J. M. Tarascon, Nat Chem 2015, 7, 19.

[13] H. Yamin, A. Gorenshtein, J. Penciner, Y. Sternberg, E. Peled, J Electrochem Soc 1988, 135, 1045.

[14] E. Peled, Y. Sternberg, A. Gorenshtein, Y. Lavi, J Electrochem Soc 1989, 136, 1621.

[15] C. Erhardt, Ş. Sörgel, S. Meinhard, T. Sörgel, J Power Sources 2015, 296, 70.

[16] Q. Zeng, X. Leng, K.-H. Wu, I. R. Gentle, D.-W. Wang, Carbon 2015, 93, 611.

[17] J.-L. Shi, H.-J. Peng, L. Zhu, W. Zhu, Q. Zhang, Carbon 2015, 92, 96.

[18] C.-Y. Fan, H.-H. Li, L.-L. Zhang, H.-Z. Sun, X.-L. Wu, H.-M. Xie, J.-P. Zhang, Physical Chemistry Chemical Physics 2015, 17, 23481.

[19] G. M. Zhou, L. Li, C. Q. Ma, S. G. Wang, Y. Shi, N. Koratkar, W. C. Ren, F. Li, H. M. Cheng, Nano Energy 2015, 11, 356.

[20] J. W. Zhou, X. S. Yu, X. X. Fan, X. J. Wang, H. W. Li, Y. Y. Zhang, W. Li, J. Zheng, B. Wang, X. G. Li, J Mater Chem A 2015, 3, 8272.

[21] N. Ding, S. W. Chien, T. S. A. Hor, Z. Liu, Y. Zong, J Power Sources 2014, 269, 111.

[22] H. Chen, C. Wang, Y. Dai, S. Qiu, J. Yang, W. Lu, L. Chen, Nano Lett 2015, 15, 5443.

[23] Q. Zhao, X. F. Hu, K. Zhang, N. Zhang, Y. X. Hu, J. Chen, Nano Lett 2015, 15, 721.

[24] J. Brückner, S. Thieme, H. T. Grossmann, S. Dörfler, H. Althues, S. Kaskel, J Power Sources 2014, 268, 82.

[25] X. Li, A. Lushington, J. Liu, R. Li, X. Sun, Chem Commun 2014, $50,9757$.

[26] J. Yan, X. Liu, M. Yao, X. Wang, T. K. Wafle, B. Li, Chemistry of Materials 2015, $27,5080$.

[27] X. Q. Yu, H. L. Pan, Y. N. Zhou, P. Northrup, J. Xiao, S. Bak, M. Z. Liu, K. W. Nam, D. Y. Qu, J. Liu, T. P. Wu, X. Q. Yang, Advanced Energy Materials 2015, 5.

[28] S. H. Yeon, W. Ahn, K. H. Shin, C. S. Jin, K. N. Jung, J. D. Jeon, S. Lim, Y. Kim, Korean J Chem Eng 2015, 32, 867.

[29] H. Shao, C. Li, N. Liu, W. Wang, H. Zhang, X. Zhao, Y. Huang, Rsc Adv 2015, 5, 47757.

[30] Z. Zhang, Q. Li, K. Zhang, W. Chen, Y. Lai, J. Li, J Power Sources 2015, 290, 159.

[31] Q. Sun, X. Fang, W. Weng, J. Deng, P. Chen, J. Ren, G. Guan, M. Wang, H. Peng, Angewandte Chemie International Edition 2015, 54, 10539.

[32] Q. Sun, B. He, X.-Q. Zhang, A.-H. Lu, ACS Nano 2015, 9, 8504.

[33] J. Liu, W. Li, L. Duan, X. Li, L. Ji, Z. Geng, K. Huang, L. Lu, L. Zhou, Z. Liu, W. Chen, L. Liu, S. Feng, Y. Zhang, Nano Lett 2015, 15, 5137.

[34] M. Agostini, S. Xiong, A. Matic, J. Hassoun, Chemistry of Materials 2015, 27, 4604.

[35] L. Zeng, Y. Jiang, J. Xu, M. Wang, W. Li, Y. Yu, Nanoscale 2015, 7, 10940.

[36] B. Ding, Z. Chang, G. Xu, P. Nie, J. Wang, J. Pan, H. Dou, X. Zhang, Acs Appl Mater Inter 2015, 7, 11165.

[37] A. Manthiram, S.-H. Chung, C. Zu, Adv Mater 2015, 27, 1980.

[38] N. Yan, X. F. Yang, W. Zhou, H. Z. Zhang, X. F. Li, H. M. Zhang, Rsc Adv 2015, 5, 26273.

[39] G. M. Zhou, Y. B. Zhao, A. Manthiram, Advanced Energy Materials 2015, 5.

[40] X. Gu, C. Lai, F. Liu, W. Yang, Y. Hou, S. Zhang, J Mater Chem A 2015, 3, 9502.

[41] C.-N. Lin, W.-C. Chen, Y.-F. Song, C.-C. Wang, L.-D. Tsai, N.-L. Wu, J Power Sources 2014, 263, 98. 


\section{WILEY-VCH}

[42] H. Yao, K. Yan, W. Li, G. Zheng, D. Kong, Z. W. Seh, V. K. Narasimhan, Z. Liang, Y. Cui, Energ Environ Sci 2014, 7, 3381.

[43] J. Xu, J. Shui, J. Wang, M. Wang, H.-K. Liu, Acs Nano 2014, 8, 10920.

[44] B. Wang, S. M. Alhassan, S. T. Pantelides, Physical review applied 2014, 2.

[45] S.-H. Chung, A. Manthiram, Adv Funct Mater 2014, 24, 5299.

[46] Q. Pang, D. Kundu, M. Cuisinier, L. F. Nazar, Nat Commun 2014, 5.

[47] J. R. Akridge, Y. V. Mikhaylik, N. White, Solid State Ionics 2004, 175, 243.

[48] B. Zhang, X. Qin, G. R. Li, X. P. Gao, Energ Environ Sci 2010, 3, 1531.

[49] M. Nagao, A. Hayashi, M. Tatsumisago, Electrochim Acta 2011, 56, 6055.

[50] Y. Zhang, Z. Bakenov, Y. Zhao, A. Konarov, Q. Wang, P. Chen, Ionics 2014, 20, 803.

[51] J. Yan, X. Liu, X. Wang, B. Li, J Mater Chem A 2015, 3, 10127.

[52] J. Song, M. L. Gordin, T. Xu, S. Chen, Z. Yu, H. Sohn, J. Lu, Y. Ren, Y. Duan, D. Wang, Angewandte Chemie International Edition 2015, 54, 4325.

[53] J. Song, Z. Yu, M. L. Gordin, D. Wang, Nano Lett 2016, 16, 864.

[54] S. Chen, F. Dai, M. L. Gordin, Z. Yu, Y. Gao, J. Song, D. Wang, Angewandte Chemie 2016, 128, 4303.

[55] K. Xu, Chemical Reviews 2004, 104, 4303.

[56] J. Gao, M. A. Lowe, Y. Kiya, H. D. Abruña, The Journal of Physical Chemistry C 2011, 115, 25132.

[57] K. Xu, Chemical Reviews 2014, 114, 11503.

[58] C. Barchasz, J.-C. Leprêtre, S. Patoux, F. Alloin, Electrochim Acta 2013, 89, 737.

[59] X. Liang, M. Zhang, M. R. Kaiser, X. Gao, K. Konstantinov, R. Tandiono, Z. Wang, H.-K. Liu, S.-X. Dou, J. Wang, Nano Energy 2015, 11, 587.

[60] L. Carbone, M. Gobet, J. Peng, M. Devany, B. Scrosati, S. Greenbaum, J. Hassoun, J Power Sources 2015, 299, 460.

[61] D.-R. Chang, S.-H. Lee, S.-W. Kim, H.-T. Kim, J Power Sources 2002, 112, 452.

[62] Y. V. Mikhaylik, J. R. Akridge, J Electrochem Soc 2003, 150, A306.

[63] Y. V. Mikhaylik, J. R. Akridge, J Electrochem Soc 2004, 151, A1969.

[64] W. A. Henderson, The Journal of Physical Chemistry B 2006, 110, 13177.

[65] H.-S. Ryu, H.-J. Ahn, K.-W. Kim, J.-H. Ahn, K.-K. Cho, T.-H. Nam, J.-U. Kim, G.-B. Cho, J Power Sources 2006, 163, 201.

[66] H. S. Kim, T.-G. Jeong, N.-S. Choi, Y.-T. Kim, Ionics 2013, 19, 1795.

[67] S.-I. Tobishima, H. Yamamoto, M. Matsuda, Electrochim Acta 1997, 42, 1019.

[68] Y. Mikhaylik, I. Kovalev, R. Schock, K. Kumaresan, J. Xu, J. Affinito, "High energy rechargeable Li-S cells for EV application: Status, remaining problems and solutions", presented at ECS Transactions, 2010.

[69] K. H. Wujcik, T. A. Pascal, C. D. Pemmaraju, D. Devaux, W. C. Stolte, N. P. Balsara, D. Prendergast, Advanced Energy Materials 2015, 5, 1500285.

[70] Q. Wang, J. Zheng, E. Walter, H. Pan, D. Lv, P. Zuo, H. Chen, Z. D. Deng, B. Y. Liaw, X. Yu, X. Yang, J.-G. Zhang, J. Liu, J. Xiao, J Electrochem Soc 2015, 162, A474.

[71] M. Cuisinier, C. Hart, M. Balasubramanian, A. Garsuch, L. F. Nazar, Advanced Energy Materials 2015, 5, 1401801.

[72] A. Rosenman, E. Markevich, G. Salitra, D. Aurbach, A. Garsuch, F. F. Chesneau, Advanced Energy Materials 2015, 5, 1500212.

[73] R. Younesi, G. M. Veith, P. Johansson, K. Edstrom, T. Vegge, Energ Environ Sci 2015, 8, 1905.

[74] W. Linert, A. Camard, M. Armand, C. Michot, Coordination Chemistry Reviews 2002, 226, 137.

[75] G. Schmidt, I. Cayrefourcq, S. Paillet, J. Fréchette, F. Barray, D. Clément, P. Hovington, A. Guerfi, K. Zaghib, Meeting Abstracts 2014, MA2014-04, 741. 


\section{WILEY-VCH}

[76] L. Niedzicki, S. Grugeon, S. Laruelle, P. Judeinstein, M. Bukowska, J. Prejzner, P. Szczeciñski, W. Wieczorek, M. Armand, J Power Sources 2011, 196, 8696.

[77] M. Carboni, R. Spezia, S. Brutti, The Journal of Physical Chemistry C 2014, 118, 24221.

[78] J. Foropoulos, D. D. DesMarteau, Inorganic Chemistry 1984, 23, 3720.

[79] L. Suo, O. Borodin, T. Gao, M. Olguin, J. Ho, X. Fan, C. Luo, C. Wang, K. Xu, Science 2015, 350, 938.

[80] L. Suo, Y.-S. Hu, H. Li, M. Armand, L. Chen, Nat Commun 2013, 4, 1481.

[81] H. Pan, X. Wei, W. A. Henderson, Y. Shao, J. Chen, P. Bhattacharya, J. Xiao, J. Liu, Advanced Energy Materials 2015, 5, 1500113.

[82] H. Pan, K. S. Han, M. Vijayakumar, J. Xiao, R. Cao, J. Chen, J. Zhang, K. T. Mueller, Y. Shao, J. Liu, Acs Appl Mater Inter 2017, 9, 4290.

[83] S. Kim, Y. Jung, S.-J. Park, Electrochim Acta 2007, 52, 2116.

[84] R. Cao, J. Chen, K. S. Han, W. Xu, D. Mei, P. Bhattacharya, M. H. Engelhard, K. T. Mueller, J. Liu, J.-G. Zhang, Adv Funct Mater 2016, 26, 3059.

[85] A. Rosenman, E. Markevich, G. Salitra, D. Aurbach, A. Garsuch, F. F. Chesneau, Advanced Energy Materials 2015, 5, n/a.

[86] D. Aurbach, E. Pollak, R. Elazari, G. Salitra, C. S. Kelley, J. Affinito, J Electrochem Soc 2009, 156, A694.

[87] S. Kinoshita, K. Okuda, N. Machida, T. Shigematsu, J Power Sources 2014, 269, 727.

[88] F. Wu, J. Qian, R. Chen, J. Lu, L. Li, H. Wu, J. Chen, T. Zhao, Y. Ye, K. Amine, Acs Appl Mater Inter 2014, 6, 15542.

[89] S. Xiong, X. Kai, X. Hong, Y. Diao, Ionics 2012, 18, 249.

[90] C. Barchasz, J.-C. Leprêtre, F. Alloin, S. Patoux, J Power Sources 2012, 199, 322.

[91] S. Xiong, K. Xie, Y. Diao, X. Hong, Electrochim Acta 2012, 83, 78.

[92] S. Xiong, K. Xie, Y. Diao, X. Hong, J Power Sources 2013, 236, 181.

[93] S. Xiong, K. Xie, Y. Diao, X. Hong, J Power Sources 2014, 246, 840.

[94] S. S. Zhang, Electrochim Acta 2012, 70, 344.

[95] S. S. Zhang, J Electrochem Soc 2012, 159, A920.

[96] G. Li, C. Wang, W. Cai, Z. Lin, Z. Li, S. Zhang, NPG Asia Mater 2016, 8, 317

[97] H. Xu, L. Qie, A. Manthiram, Nano Energy 2016, 26, 224.

[98] D. Sun, Y. Hwa, Y. Shen, Y. Huang, E. J. Cairns, Nano Energy 2016, 26, 524.

[99] X. a. Chen, Z. Xiao, X. Ning, Z. Liu, Z. Yang, C. Zou, S. Wang, X. Chen, Y. Chen, S. Huang, Advanced Energy Materials 2014, 4, 1301988.

[100] D.-W. Wang, G. Zhou, F. Li, K.-H. Wu, G. Q. Lu, H.-M. Cheng, I. R. Gentle, Physical Chemistry Chemical Physics 2012, 14, 8703.

[101] T. Takahashi, M. Yamagata, M. Ishikawa, Progress in Natural Science: Materials International 2015, 25, 612 .

[102] Y. Xu, Y. Wen, Y. Zhu, K. Gaskell, K. A. Cychosz, B. Eichhorn, K. Xu, C. Wang, Adv Funct Mater 2015, 25, 4312.

[103] S. Zheng, P. Han, Z. Han, H. Zhang, Z. Tang, J. Yang, Sci Rep-Uk 2014, 4, 4842.

[104] J. Guo, Y. Xu, C. Wang, Nano Lett 2011, 11, 4288.

[105] E. Markevich, G. Salitra, Y. Talyosef, F. Chesneau, D. Aurbach, J Electrochem Soc 2017, 164, A6244.

[106] S. Y. Zheng, Y. Chen, Y. H. Xu, F. Yi, Y. J. Zhu, Y. H. Liu, J. H. Yang, C. S. Wang, Acs Nano 2013, 7, 10995.

[107] N. Azimi, Z. Xue, I. Bloom, M. L. Gordin, D. Wang, T. Daniel, C. Takoudis, Z. Zhang, Acs Appl Mater Inter 2015, 7, 9169.

[108] M. L. Gordin, F. Dai, S. Chen, T. Xu, J. Song, D. Tang, N. Azimi, Z. Zhang, D. Wang, Acs Appl Mater Inter 2014, 6, 8006. 


\section{WILEY-VCH}

[109] S. Chen, Z. Yu, M. L. Gordin, R. Yi, J. Song, D. Wang, Acs Appl Mater Inter 2017, 9, 6959.

[110] S. Chen, Y. Gao, Z. Yu, M. L. Gordin, J. Song, D. Wang, Nano Energy 2017, 31, 418. 